\title{
Estratigrafia dos depósitos iniciais do rifte no Campo de Furado, região de São Miguel dos Campos, Bacia de Sergipe-Alagoas
}

\author{
Cláudio Borba ${ }^{1}$, Paulo Sérgio Gomes Paim² \& Antonio Jorge Vasconcellos Garcia ${ }^{3}$
}

\begin{abstract}
Resumo Baseado em perfis eletrorradioativos, testemunhos, amostras de calha e sísmica 3D este trabalho apresenta o arcabouço estratigráfico de média resolução das formações Feliz Deserto, Barra de Itiúba e Penedo dirigido ao zoneamento de reservatórios no Campo de Furado (Bacia de Sergipe-Alagoas). Também discute a influência da tectônica na sedimentação ao início do estágio rifte da bacia. A Seqüência J20-K5 (formações Candeeiro, Bananeiras e Serraria - andares Dom João/Rio da Serra), lacustre rasa e fluvial, passa concordantemente para a Seqüência K10-K20 (Formação Feliz Deserto, Andar Rio da Serra), compondo uma única seqüência de $2^{\mathrm{a}}$ ordem. A Seqüência K10-K20, formada por depósitos de lago raso, registra um gradual aumento do tectonismo, com estratos passando de paralelos para divergentes. A discordância angular Pré-Aratu separa as sequiências K10K20 e K34-K36 e marca um importante evento regional de soerguimento. Um novo pulso de subsidência, agora mais acelerada, resultou na deposição da Seqüência K34-K36. Em sua porção inferior (andares Aratu a Buracica - Formação Barra de Itiúba) possui depósitos lacustres e deltaicos que registram grandes oscilações batimétricas. As seqüências de $3^{a}$ ordem superiores retratam o preenchimento da bacia por depósitos fluviais, a última correspondendo à Formação Penedo (Eo-Jiquiá). No Andar Alagoas, um grande número de falhas pós-deposicionais de grande rejeito seccionou todo o conjunto. Contudo, existem evidências de uma discreta atuação de falhas desde o Andar Rio da Serra, formando depocentros e altos localizados, ligadas a dobras de crescimento relacionadas à iniciação e propagação de falhas em profundidade, feições essas típicas dos estágios iniciais do rifteamento.
\end{abstract}

Palavras-chave: Bacia de Sergipe-Alagoas, Formação Feliz Deserto, Formação Barra de Itiúba, Rifte.

\begin{abstract}
Stratigraphy of the early rifting deposits of the Furado Field, São Miguel dos Campos region, Sergipe-Alagoas Basin. Based on well logs, cuttings, cores and 3D seismic this work presents the $3^{\text {rd }}$ order stratigraphic framework of the Feliz Deserto, Barra de Itiúba and Penedo formations and its relationship with the Furado Oilfield reservoir zones (Sergipe-Alagoas Basin). It also discusses the impact of tectonics on sedimentation during the early rifting stages. The J20-K5 Sequence (Candeeiro, Bananeiras and Serraria formations of the Dom João / Rio da Serra stages) comprise mostly shallow lacustrine and fluvial deposits that conformably change upwards to the K10-K20 Sequence (Feliz Deserto Formation of the Rio da Serra Stage), both making up a single $2^{\text {nd }}$ order sequence. The K10-K20 sequences encompass shallow lacustrine facies that record a gradual growth on tectonic activity, as pointed by the upward change from parallel to divergent strata. The Pre-Aratu Unconformity bounds the K10-K20 and K34-K36 sequences and represents an important regional uplift event. A new subsidence pulse resulted in the deposition of the K34-K36 Sequence (Aratú to Buracica stages). Its lower $3^{\text {rd }}$ order sequences encompass lacustrine and deltaic deposits and show evidence of higher-scale lake-level fluctuations relative to the K10-K20 Sequence. The upper $3^{\text {rd }}$ order sequences represent the last stages of basin filling (coarse-grained fluvial deposits), the uppermost being equivalent to the Penedo Formation (Jiquiá Stage). Later, in the Alagoas Stage, a huge number of large, post-depositional normal faults deformed the entire succession although a gentle tectonic activity, related to fault propagation folding, a typical feature of early rifting, is identifiable since the late Rio da Serra Stage.
\end{abstract}

Keywords: Sergipe-Alagoas Basin, Feliz Deserto Formation, Barra de Itiúba Formation, Rift.

INTRODUÇÃO O Campo de Furado, localizado na porção alagoana da Bacia de Sergipe-Alagoas (Fig. 1), apresenta de forma praticamente completa o registro estratigráfico dos estágios iniciais do rifteamento, fato incomum nesta bacia de evolução complexa, onde ausências estratigráficas produzidas por falhas ou não deposição são freqüentes. Por se tratar de um campo de petróleo maduro, também dispõe de informações estáticas e dinâmicas que permitem calibrar as interpretações geológicas.

As unidades estratigráficas aqui estudadas (formações Feliz Deserto, Barra de Itiúba e Penedo, Fig. 2), totalizam $2600 \mathrm{~m}$ de sedimentos depositados ao longo de cerca de 20Ma, durante o Cretáceo Inferior (Berriasiano? a Barremiano?, andares locais Rio da Serra a Eo-Jiquiá).

O objetivo do trabalho é compor um arcabouço estratigráfico integrado de média resolução $\left(3^{\mathrm{a}}\right.$ ordem $)$ 

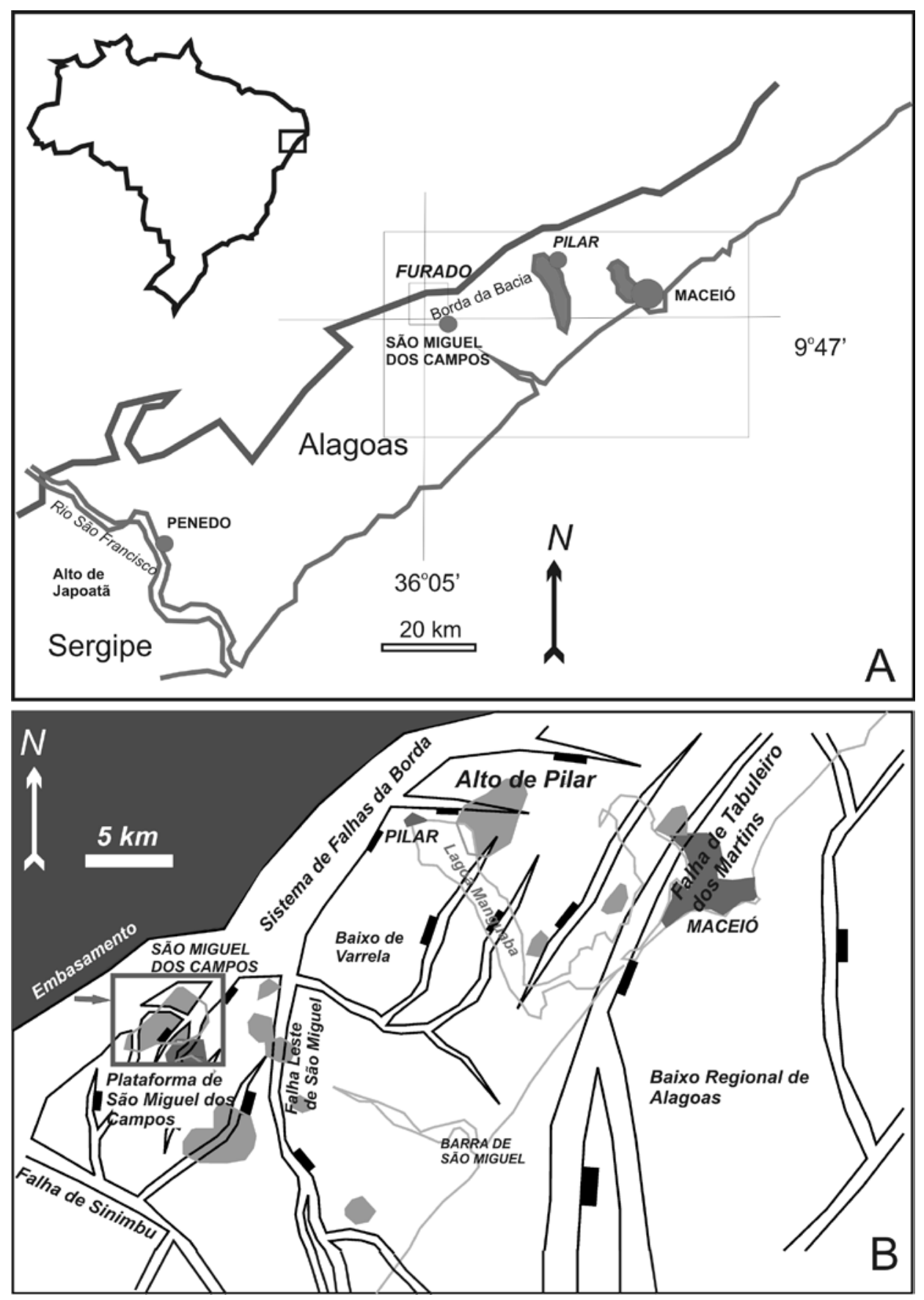

Figura 1 - A) Mapa de localização da área estudada, B) Mapa estrutural regional do embasamento (modificado de Chiossi 1997). Em cinza, os principais campos de petróleo.

dessas unidades, em especial da ainda pouco estudada Formação Feliz Deserto, adaptado à nomenclatura estratigráfica recentemente proposta para a Bacia de Sergipe-Alagoas (Campos Neto et al. 2007). Este arcabouço permitirá integrar a estratigrafia de produção (zoneamento de reservatórios) nos diversos campos de petróleo da porção alagoana da bacia. Além disso, busca entender a influência da tectônica na sedimentação, em especial se as falhas atuaram na acomodação numa época em que o tectonismo é tido como brando.

Para a realização do trabalho, foram utilizadas informações de 26 poços (amostras de calha, perfis, testemunhos e bioestratigrafia de ostracodes) e sísmica 3D. O trabalho se concentrou região do Campo de Furado, mas informações adicionais da porção sul da Sub-bacia de Alagoas também foram utilizadas, com a finalidade de dar suporte regional às interpretações.

As etapas para atingir o objetivo proposto foram: revisão de descrição de testemunhos, correlação rocha-perfil, identificação de superfícies com significado estratigráfico, correlação entre poços, confecção de seções e mapas estratigráficos (isópacas e isólitas) e mapeamento estrutural das superfícies estratigráficas. 


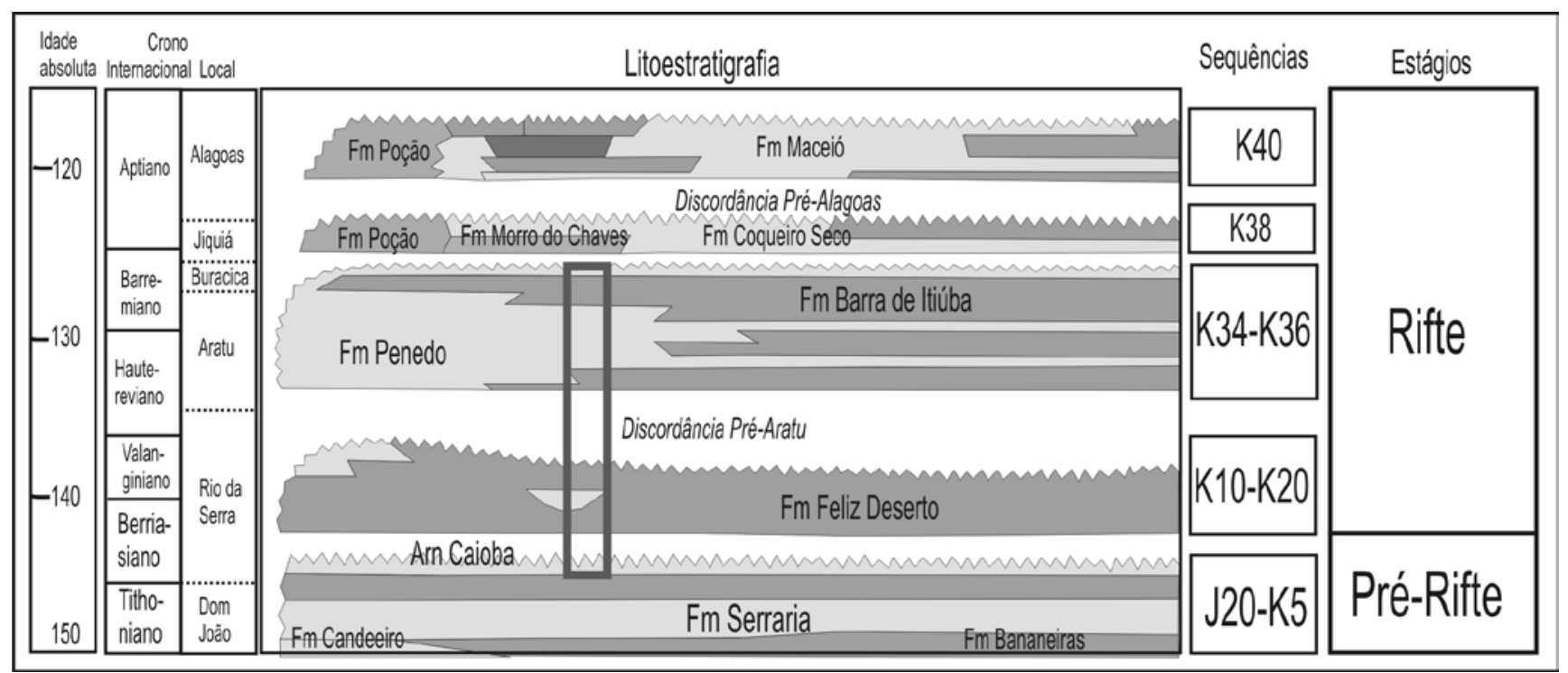

Figura 2 - Carta estratigráfica do rifte da Sub-bacia de Sergipe-Alagoas (modificada de Campos Neto et al. 2007). O retângulo no interior da figura localiza o intervalo estudado neste trabalho.

TRABALHOS ANTERIORES A estratigrafia da Bacia de Sergipe-Alagoas foi organizada por Schaller (1969), que descreveu a Formação Barra de Itiúba como constituída por folhelhos cinza esverdeados e negros, intercalados com arenitos finos e calcários. Pelo mesmo autor a Formação Penedo foi descrita como formada por arenitos médios a conglomeráticos, e presença secundária de siltitos e folhelhos. Na borda da porção sergipana da bacia também foram reportados conglomerados, compondo a Formação Rio Pitanga. Essas unidades foram interpretadas como depositadas em um amplo sistema proximal-distal, onde os conglomerados da Formação Rio Pitanga seriam os leques aluviais da borda da bacia, a Formação Penedo os depósitos fluviais e a Formação Barra de Itiúba corresponderia aos depósitos deltaicos e lacustres.

Dentro da Formação Barra de Itiúba, Galm e Santos (1994) reconheceram a Discordância Pré-Aratu, baseado na ausência regional de 3 subzonas de ostracodes, totalizando um hiato de até $5 \mathrm{Ma}$ em praticamente toda a bacia. Na revisão da carta estratigráfica, Feijó (1994) a considerou como sendo a discordância inicial do rifte. Bueno (2004) identificou esta discordância em diversas bacias do Atlântico Sul, e a definiu como a "discordância de propagação do rifte", na passagem do Valanginiano para o Hautereviano. Em função dessa importante quebra no registro sedimentar, Campos Neto et al. (2007) resgataram a denominação Formação Feliz Deserto (Seqüência K10-K20), utilizada pelo grupo de Estudos de Bacia da Petrobras na década de 1960, e incluída na porção basal da Formação Barra de Itiúba em revisões posteriores (Schaller 1969, Feijó 1994).

$\mathrm{O}$ rifte da bacia de Sergipe-Alagoas é descrito como policíclico (Chang et al. 1992, Destro 1994), sendo as unidades aqui estudadas representantes dos ciclos iniciais, quando a atuação das falhas na geração do espaço de acomodação ainda era incipiente. Para Chagas et al. (1993), durante a deposição das formações Barra de Itiúba e Penedo, a Bacia de Sergipe-Alagoas seria a margem flexural de um grande rifte assimétrico, com a borda ativa provavelmente localizada na África (Bacia do Sul do Gabão). Mais recentemente, Hamsi Jr. \& Karner (2005) propuseram um modelo de distensão crustal dependente de profundidade, onde a sedimentação sin-rifte seria caracterizada por um amplo sag, com pouquíssima atuação das falhas na acomodação. A rara presença de conglomerados e os refletores essencialmente paralelos observados em seções sísmicas regionais dão o suporte para esta hipótese.

O momento exato do início do rifteamento ainda é controverso, dependendo do critério utilizado na sua demarcação. Na última revisão da coluna (Campos Neto et al. 2007), o início do rifte foi marcado na base da Formação Feliz Deserto (Sequência K10-K20), quando o sistema fluvial da Formação Serraria foi rapidamente afogado, dando origem a um grande lago.

Em estudo estratigráfico regional, Chiossi (1997) elaborou um modelo para a sedimentação da Seqüência K34-K36 (em seu trabalho denominada Seqüência IIa), onde o tectonismo seria responsável pela deposição dos tratos de lago baixo (ou regressivo inicial, como preferiu o autor) das seqüências de $3^{\mathrm{a}}$ ordem, produzidos pelo rebaixamento tectônico do nível do lago e soerguimento relativo da margem flexural. Já os tratos transgressivos e de lago alto (regressivo final) seriam de natureza predominantemente climática, quando o espaço gerado no pulso tectônico foi preenchido por água e sedimentos.

ESTRUTURA O Campo de Furado situa-se no compartimento da bacia denominado Plataforma de São Miguel dos Campos, formado por degraus separados por falhas de 
direção nordeste, próximas à atual borda da bacia. O modelo estrutural foi elaborado por Góes et al. (1986), amparado em dados de poços. Com a aquisição sísmica $3 \mathrm{D}$ e a perfuração de poços adicionais, o modelo foi aprimorado e expandido para áreas adjacentes, e pode ser resumido no mapa da figura 3 e na seção sísmica da figura 4.

Furado é dividido em dois compartimentos principais (Fig. 3): uma estrutura dômica relacionada ao drag reverso da falha de borda da bacia; e a área de Fazenda Tomada, um horst entre a estrutura dômica e o adjacente Campo de Cidade de São Miguel dos Campos. Toda a área é cortada por falhas conjugadas normais de direção norte-nordeste, e por falhas de transferência de direção noroeste. A grande maioria das falhas é de idade Alagoas (Meso-Aptiano?/Eo-Albiano?), e quase sempre atuam como selos, isolando os reservatórios de petróleo em blocos hidraulicamente independentes.

A F19 é a principal falha do sistema da borda, com pelo menos $3000 \mathrm{~m}$ de rejeito e direção $\mathrm{N} 60^{\circ} \mathrm{E}$. Provavelmente não se trata de uma falha ativa na época da deposição das unidades aqui tratadas, quando o limite da bacia se situava mais a oeste, mas formada em pulsos mais tardios e intensos, no Andar Alagoas. Esta interpretação é reforçada principalmente pela ausência de conglomerados e de espessamento significativo de seção junto à falha de borda. As falhas F2 e F52, de direção $\mathrm{N} 30^{\circ} \mathrm{E}$, também apresentam rejeitos expressivos (até $500 \mathrm{~m}$ ) e estão dispostas em padrão de reveza- mento e conectadas com as falhas de menor magnitude, com mergulho paralelo à falha da borda (cerca de $35^{\circ}$ para sudeste). A Falha F1 é conjugada às falhas acima, e com elas delineia o Alto de Fazenda Tomada. As falhas de transferência de direção noroeste acomodam as diferenças de movimentação das falhas de direção norte e nordeste. Apresentam alto ângulo e são de difícil imageamento sísmico. Não são necessariamente de deslocamento direcional, e sim falhas normais de direção perpendicular às falhas principais da bacia (falhas de alívio sensu Destro 1995).

O gráben limitado pelas falhas F19 e F1, chamado aqui de Depocentro Furado, é uma área que apresenta discreto espessamento dos estratos desde o final do Andar Rio da Serra, sugerindo tectonismo atuante durante a sedimentação, conforme será discutido adiante.

FÁCIES E ASSOCIAÇÕES DE FÁCIES As fácies e associações de fácies interpretadas a partir de testemunhos já foram objetos de trabalhos anteriores (Cruz e Galm 1994, Chiossi 1997), que forneceram uma descrição bastante completa da Formação Barra de Itiúba. Por outro lado, as formações Feliz Deserto e Penedo estão pobremente amostradas na área, levando à necessidade de se recorrer a testemunhos de outros campos ou a afloramentos análogos. Nesses casos, a Formação Penedo foi descrita em testemunhos no Campo de Pilar, e a Formação Feliz Deserto em sondagens para pesqui-

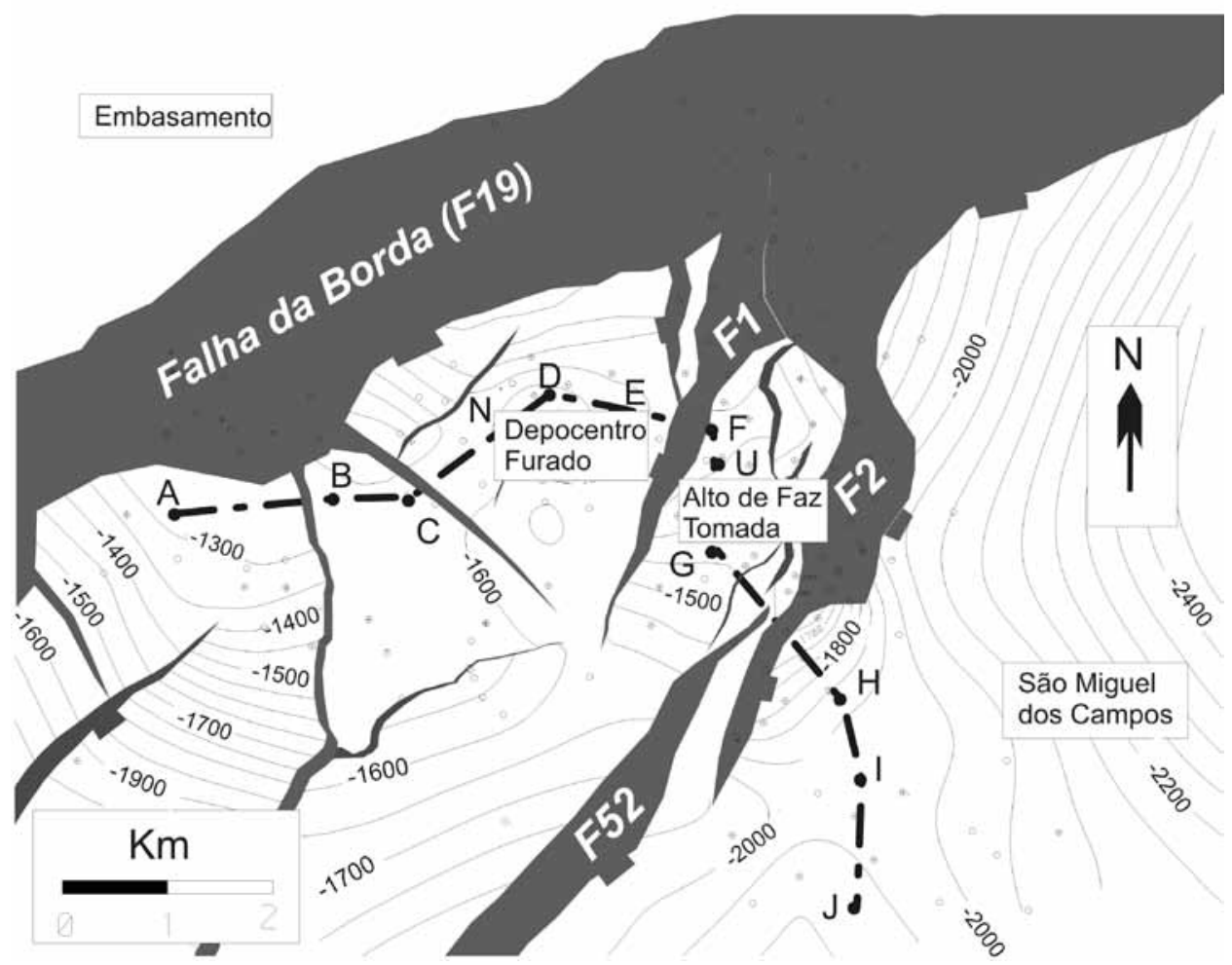

Figura 3 - Mapa estrutural da base da Seqüência K34/10 (Discordância PréAratu). A Falha F19 é a atual falha de borda da bacia, e as falhas F1, F2 e F52 delimitam o horst de Fazenda Tomada. A linha A-J localiza a seção sísmica arbitrária da figura 4 e a seção estratigráfica da figura 6. 


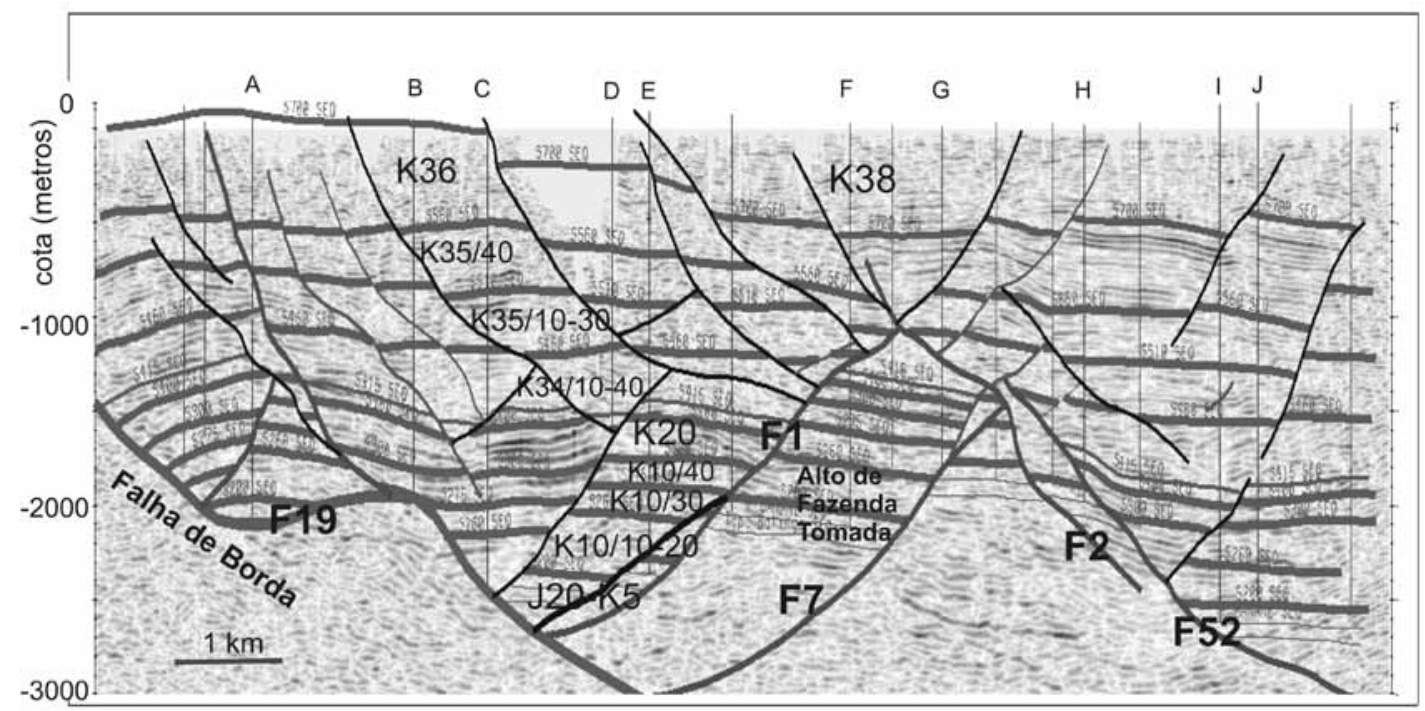

Figura 4 - Seção sísmica arbitrária em profundidade do Campo de Furado, com os principais limites de seqüencia e as falhas mais importantes assinaladas.

sa mineral e afloramentos no Alto de Japoatã, em Sergipe (Garcia 1991, Barreiro 2004). Amostras de calha também foram aqui utilizadas para a obtenção da granulometria e das curvas de coloração dos sedimentos, complementando os dados de testemunhos e de perfis de poços. As fácies e associações de fácies resultantes, baseadas nos trabalhos acima citados, e aqui integradas, estão sumarizadas na tabela 1 .

DETALHAMENTO EM SEQUENCIAS DE $3^{\mathrm{a}}$ ORDEM Neste trabalho, a nomenclatura das sequências segue a padronização das colunas estratigráficas das bacias brasileiras, originalmente proposta por Feijó (1994) e recentemente revisada por Campos Neto et al. (2007) para o caso da Bacia de Sergipe-Alagoas. Para a hierarquização dos estratos em sequências e seus tratos de sistemas, foram utilizados os critérios brevemente resumidos abaixo. A tabela 2 apresenta um resumo da arquitetura estratigráfica da área estudada.

As Sequências de $1^{\mathrm{a}}$ ordem compreendem todo um estágio de evolução da bacia (rifte), portanto, todo o empilhamento aqui estudado faz parte de uma sequência de $1^{\mathrm{a}}$ ordem. As sequências de $2^{\mathrm{a}}$ ordem correspondem aos ciclos tectônicos do rifte, que normalmente imprimem mudanças de ambiente deposicional. Os limites são constituídos por discordâncias de expressão regional. Correspondem às sequências J20-K5, K10-K20, e K34-K36; de Campos Neto et al. (2007). As sequências de $3^{\mathrm{a}}$ ordem resultam de pulsos de subsidência do rifte, comumente limitados por bruscos deslocamentos de fácies, seja por eventos de exposição subaérea ou por forte progradação de deltas, a depender da localização paleogeográfica. As sequências de $3^{\mathrm{a}}$ ordem são constituídas pelos tratos de alta e baixa acomodação, ou pelos tratos de lago baixo, transgressivo e de lago alto onde predominam os depósitos lacustres e deltaicos.

Com base em quebras no padrão de empilhamen- to (Fig. 5), foram detalhadas as seqüências de $3^{\mathrm{a}}$ ordem K10/10 a K20 (subdivisões de K10-K20) e K34/10 a K36 (subdivisões de K34-K36), procurando seguir a nomenclatura adotada por Campos Neto et al. (2007). Para a Seqüência K34-K36, o fatiamento apresenta bastante similaridade, embora com diferente nomenclatura, ao realizado por Chiossi (1997). De modo geral, percebe-se a presença de ciclos iniciados por extensos corpos tabulares de arenitos flúvio-deltaicos, rapidamente cobertos por pelitos lacustres, seguidos de uma regressão normal. A paleogeografia na forma uma rampa suave (Chiossi 1997), fez com que os depósitos sejam caracterizados por uma grande continuidade lateral de sistemas fluvio-deltaicos assentados sobre limites de seqüência, sem incisões significativas (conforme Posamentier \& Allen 1999).

A seção de correlação (Fig. 6), que contém as principais superfícies rastreadas, mostra diversas ausências estratigráficas, algumas expressivas ( $>100 \mathrm{~m})$, facilmente atribuídas às falhas, e outras menores $(<50 \mathrm{~m})$, que poderiam estar associadas a erosões. Essas ausências foram confrontadas com seções sísmicas e perfis de mergulho, de modo a discriminar sua origem estrutural ou estratigráfica.

Apesar da disponibilidade de dados sísmicos 3D, há uma dificuldade na sua utilização para análise estratigráfica. Dentre os motivos, destacam-se: a) a espessura dos corpos abaixo da resolução; b) o padrão predominantemente paralelo dos estratos, com difícil reconhecimento de terminações de refletores; c) a grande quantidade de falhas, que mascaram as feições estratigráficas, d) a baixa qualidade sísmica, devido às difrações produzidas pelas falhas, quanto às limitações superficiais (obras civis e acidentes naturais) que prejudicaram a aquisição e à presença de uma cobertura com cerca de 100m de espessura de depósitos de baixa velocidade sísmica (Formação Barreiras). Mesmo assim, a sísmica foi importante no mapeamento estrutural, tendo 
Tabela 1 - Associações de fácies encontradas nas formações Feliz Deserto, Barra de Itiúba e Penedo.

\begin{tabular}{|c|c|c|c|}
\hline Ambiente & Associações de fácies & $\begin{array}{l}\text { Litologias e estruturas sedimentares } \\
\text { dominantes }\end{array}$ & Padrões em perfis elétricos \\
\hline \multirow{3}{*}{ Planície aluvial } & Canais e barras fluviais & $\begin{array}{l}\text { Arenito arcosiano médio a } \\
\text { conglomerático com estratificação } \\
\text { cruzada e granodecrescência } \\
\text { ascendente. }\end{array}$ & $\begin{array}{l}\text { Quando amalgamados formam } \\
\text { caixotes com até } 150 \mathrm{~m} \text { de espessura. } \\
\text { Quando delgados difícil diferencia-los } \\
\text { das fácies de canais distributários. }\end{array}$ \\
\hline & $\begin{array}{l}\text { Planície de inundação/ } \\
\text { lacustre raso }\end{array}$ & $\begin{array}{l}\text { Folhelho e siltito esverdeado/ } \\
\text { avermelhado com marcas de raízes } \\
\text { e gretas de ressecamento. }\end{array}$ & $\begin{array}{l}\text { Raio-gama elevado e espessura de } \\
\text { até } 10 \mathrm{~m} .\end{array}$ \\
\hline & Eólico & $\begin{array}{l}\text { Arenito fino a médio com textura } \\
\text { bimodal e estratos de queda e fluxo } \\
\text { de grãos. Mais ricos em quartzo em } \\
\text { relação as fácies fluviais. }\end{array}$ & $\begin{array}{l}\text { Caixotes com dezenas de metros de } \\
\text { espessura. Menores valores de raios } \\
\text { gama e resistividade e mais elevada } \\
\text { porosidade em relação aos depósitos } \\
\text { fluviais. }\end{array}$ \\
\hline \multirow{2}{*}{ Planície Deltaica } & Crevasse & $\begin{array}{l}\text { Arenito muito fino com } \\
\text { granocrescência ascendente e } \\
\text { laminação cruzada cavalgante. }\end{array}$ & \multirow{2}{*}{$\begin{array}{l}\text { Serrilhado (alternância dos depósitos } \\
\text { de crevasse e baía interdistributária). } \\
\text { Espessura de até } 5 \mathrm{~m} \text {. }\end{array}$} \\
\hline & Baía interdistributária & $\begin{array}{l}\text { Folhelho/siltito esverdeado muito } \\
\text { bioturbado. }\end{array}$ & \\
\hline Frente deltaica & Barra de desembocadura & $\begin{array}{l}\text { Arenito muito fino a grosso, com } \\
\text { granocrescência ascendente, } \\
\text { fluidização, estratificação } \\
\text { cruzada sigmoidal e estruturas de } \\
\text { escorregamento. }\end{array}$ & $\begin{array}{l}\text { Funil nos perfis de raios-gama } \\
\text { com espessuras de } 3 \text { a } 10 \mathrm{~m} \text {. A } \\
\text { amalgamação com os depósitos de } \\
\text { canais distributários pode resultar em } \\
\text { caixotes com até } 30 \mathrm{~m} \text { de espessura. }\end{array}$ \\
\hline Prodelta & & $\begin{array}{l}\text { Folhelho esverdeado e escuro, } \\
\text { siltito e arenito muito fino, } \\
\text { fluidizado, bioturbado e com } \\
\text { estruturas de escorregamento. }\end{array}$ & GR elevado com tendência a funil. \\
\hline \multirow{2}{*}{ Lago } & Lago profundo & $\begin{array}{l}\text { Folhelho negro, físsel, com nódulos } \\
\text { de fosfato e níveis de ostracodes, } \\
\text { pouco bioturbado. Teor de carbono } \\
\text { orgânico relativamente alto. }\end{array}$ & $\begin{array}{l}\text { Elevados valores de GR, resistividade } \\
\text { e tempo de trânsito no perfil sônico. }\end{array}$ \\
\hline & Turbidito lacustre & $\begin{array}{l}\text { Arenito muito fino, delgado, } \\
\text { maciço, com base erosiva. por } \\
\text { vezes com gradação normal, em } \\
\text { meio a folhelho lacustre. }\end{array}$ & $\begin{array}{l}\text { Padrão de GR serrilhado, espessura } \\
\text { máxima de } 2 \mathrm{~m} \text {. }\end{array}$ \\
\hline
\end{tabular}

sido fundamental no reconhecimento de falhas. Também foi possível identificar, mesmo com baixa resolução, alguns padrões, ilustrados na figura 7 .

Seqüências K10/10 a K10/30 Os estratos iniciais da Formação Feliz Deserto, compondo a Sequência $\mathrm{K} 10 / 10$, apresentam cerca de $270 \mathrm{~m}$ de espessura, com duração estimada em 2,4 Ma, depositados ao longo do Rio da Serra Inferior a Médio. A sismofácies é caracterizada por refletores paralelos de baixa amplitude e pouca continuidade. O sismograma sintético do Poço K (Fig. 7) e sua comparação com os perfis raios gama indica que este padrão de reflexão resulta de estratos dominantemente pelíticos, com pouco contraste de impedância. O contato basal com a Formação Serraria não é bem marcado em sísmica nem em perfis de mergulho.
Diferentemente do apresentado na carta estratigráfica da bacia (Fig. 2), seções geológicas de detalhe (como a da figura 8) mostram a passagem concordante da Seqüência J20-K5 para a K10/10, geometria também observada regionalmente, inclusive em afloramentos (Garcia, 1991).

Litologicamente, a base da Seqüência K10/10 é marcada no Arenito Caioba, depósitos fluviais tabulares com até $10 \mathrm{~m}$ de espessura, em geral de granulometria fina a média. Este arenito é cronoequivalente aos arenitos da Formação Água Grande, na Bacia do Recôncavo, onde apresenta espessuras muito maiores. Depósitos similares, mas progressivamente menos espessos, iniciam as seqüências subseqüentes (K10/20 a K10/40).

Segue uma sucessão monótona de folhelhos e siltitos esverdeados, e, em menor proporção avermelhados. Em afloramentos do Alto de Japoatã, em Ser- 
Tabela 2 - Resumo das seqüências deposicionais na área estudada.

\begin{tabular}{|c|c|c|c|c|c|c|c|c|c|}
\hline \multicolumn{3}{|c|}{ Sequências } & \multirow{2}{*}{$\begin{array}{l}\text { Duração } \\
\text { Aproximada } \\
\text { (Ma)* / Andar } \\
\text { local }\end{array}$} & \multirow{2}{*}{$\begin{array}{l}\text { Espessura } \\
\text { mínima/ } \\
\text { máxima }\end{array}$} & \multirow{2}{*}{$\begin{array}{l}\text { Taxa de } \\
\text { acumula- } \\
\text { ção (m/ka, } \\
\text { sedimentos } \\
\text { descom- } \\
\text { pactados) } \\
\end{array}$} & \multirow{2}{*}{$\begin{array}{l}\text { Padrão } \\
\text { estratal }\end{array}$} & \multirow{2}{*}{$\begin{array}{l}\text { Litologias } \\
\text { dominantes }\end{array}$} & \multirow{2}{*}{$\begin{array}{l}\text { Ambientes } \\
\text { deposicionais }\end{array}$} & \multirow{2}{*}{$\begin{array}{l}\text { Unidades lito- } \\
\text { estratigráficas }\end{array}$} \\
\hline $2^{\mathrm{a}}$ ordem & $\begin{array}{l}3^{\mathrm{a}} \\
\text { ordem }\end{array}$ & $\begin{array}{l}4^{a} \\
\text { ordem }\end{array}$ & & & & & & & \\
\hline K38 & & & $\begin{array}{l}\text { 1,3 (Jiquiá } \\
\text { Superior) }\end{array}$ & & $0,88-1,10$ & $\begin{array}{l}\text { Divergente para a } \\
\text { bacia e Depocentro } \\
\text { Furado. }\end{array}$ & $\begin{array}{l}\text { Arenito fino a } \\
\text { grosso, coquina e } \\
\text { folhelho negro }\end{array}$ & $\begin{array}{l}\text { leque } \\
\text { deltaico, } \\
\text { costeiro, } \\
\text { lacustre }\end{array}$ & $\begin{array}{l}\text { Formações } \\
\text { Coqueiro } \\
\text { Seco e Morro } \\
\text { do Chaves }\end{array}$ \\
\hline \multirow{16}{*}{ K34-K36 } & \multirow{4}{*}{ K36 } & 50 & \multirow{4}{*}{$\begin{array}{l}1,1 \text { (Jiquiá } \\
\text { Inferior) }\end{array}$} & \multirow{4}{*}{$400-600$} & \multirow{4}{*}{$0,77-0,89$} & \multirow{4}{*}{$\begin{array}{l}\text { Divergente para a } \\
\text { bacia e Depocentro } \\
\text { Furado. Erosão no } \\
\text { Alto de Fazenda } \\
\text { Tomada. }\end{array}$} & \multirow{4}{*}{$\begin{array}{l}\text { Arenito médio } \\
\text { a conglomera- } \\
\text { tico, raro pelito } \\
\text { esverdeado }\end{array}$} & \multirow{4}{*}{$\begin{array}{l}\text { Fluvial, } \\
\text { eólico }\end{array}$} & \multirow{4}{*}{\begin{tabular}{|l} 
Formação \\
Penedo
\end{tabular}} \\
\hline & & 40 & & & & & & & \\
\hline & & 30 & & & & & & & \\
\hline & & \begin{tabular}{|l|}
20 \\
10
\end{tabular} & & & & & & & \\
\hline & \multirow{5}{*}{$\mathrm{K} 35 / 40$} & 50 & \multirow{5}{*}{$\begin{array}{l}0,8 \text { (Buracica } \\
\text { Superior) }\end{array}$} & \multirow{5}{*}{$241-348$} & \multirow{5}{*}{$0,37-0,78$} & \multirow{5}{*}{$\begin{array}{l}\text { Divergente para a } \\
\text { bacia, Depocentro } \\
\text { Furado e bloco baixo } \\
\text { da Falha F2. }\end{array}$} & \multirow{5}{*}{$\begin{array}{l}\text { Arenito médio a } \\
\text { grosso, folhelho e } \\
\text { siltito esverdeado/ } \\
\text { avermelhado }\end{array}$} & \multirow{5}{*}{$\begin{array}{l}\text { Fluvial, } \\
\text { deltaico }\end{array}$} & \multirow{5}{*}{$\begin{array}{l}\text { Transição } \\
\text { Formação } \\
\text { Barra de } \\
\text { Itiúba (distal) } \\
\text { /Fm Penedo } \\
\text { (proximal) }\end{array}$} \\
\hline & & 40 & & & & & & & \\
\hline & & 30 & & & & & & & \\
\hline & & 20 & & & & & & & \\
\hline & & 10 & & & & & & & \\
\hline & $\mathrm{K} 35 / 30$ & & \multirow{3}{*}{$\begin{array}{l}\text { 2,7 (Buracica } \\
\text { Inferior) }\end{array}$} & \multirow{3}{*}{$230-425$} & \multirow{3}{*}{$0,29-0,33$} & \multirow{3}{*}{$\begin{array}{l}\text { Levemente } \\
\text { divergente para a } \\
\text { bacia e Depocentro } \\
\text { Furado }\end{array}$} & \multirow{3}{*}{$\begin{array}{l}\text { Pelito, incluindo } \\
\text { folhelho negro } \\
\text { e arenito grosso } \\
\text { basal, passando } \\
\text { a fino } \\
\end{array}$} & & \\
\hline & $\mathrm{K} 35 / 20$ & & & & & & & & \\
\hline & $\mathrm{K} 35 / 10$ & & & & & & & & \\
\hline & K34/40 & & & & & & Pelito lacustre, & & \\
\hline & $\mathrm{K} 34 / 30$ & & & & & Levemente & incluindo & Deltaico, & Formação \\
\hline & $\mathrm{K} 34 / 20$ & & 5,6 (Aratu) & $307-443$ & $0,20-0,28$ & $\begin{array}{l}\text { divergente para a } \\
\text { bacia e Depocentro }\end{array}$ & $\begin{array}{l}\text { folnelho negro } \\
\text { e arenito grosso }\end{array}$ & lacustre & Itiúba \\
\hline & $\mathrm{K} 34 / 10$ & & & & & Furado & $\begin{array}{l}\text { basal, passando } \\
\text { a fino }\end{array}$ & & \\
\hline & & 50 & & & & & & & \\
\hline & & 40 & & & & bacia e Depocentro & Siltito e folhelho & & \\
\hline & K20 & 30 & Serra Superior) & $100-249$ & $0,10-0,14$ & Furado. Parcialmente & $\begin{array}{l}\text { esverdeado, } \\
\text { arenito fino a }\end{array}$ & Deltaico, & \\
\hline & & 20 & & & & $\begin{array}{l}\text { erodida no Alto de } \\
\text { Fazenda Tomada }\end{array}$ & grosso & Lacustre & \\
\hline & & 10 & & & & & & & \\
\hline & $\mathrm{K} 10 / 40$ & & $\begin{array}{l}\text { 1,2 (Rio da } \\
\text { Serra Médio) }\end{array}$ & $\begin{array}{l}104- \\
162^{* *}\end{array}$ & $0,31-0,33$ & $\begin{array}{l}\text { Levemente } \\
\text { divergente para o } \\
\text { Depocentro Furado }\end{array}$ & $\begin{array}{l}\text { Siltito e folhelho } \\
\text { esverdeado e } \\
\text { avermelhado, } \\
\text { com aumento } \\
\text { da ocorrência } \\
\text { de arenito em } \\
\text { direção ao topo } \\
\end{array}$ & & \\
\hline $\begin{array}{l}\mathrm{J} 2 \mathrm{U}-\mathrm{K} 5- \\
\mathrm{K} 10-\mathrm{K} 20\end{array}$ & K10/30 & & $\begin{array}{l}2,2 \text { (Rio da } \\
\text { Serra Inferior) }\end{array}$ & $\begin{array}{l}132- \\
192 * * \\
\end{array}$ & $0,17-0,19$ & Paralelo & $\begin{array}{l}\text { Siltito e folhelho } \\
\text { esverdeado e }\end{array}$ & $\begin{array}{l}\text { Lacustre } \\
\text { raso, planície }\end{array}$ & Feliz Deserto \\
\hline & $\mathrm{K} 10 / 20$ & & 2,4 (Rio da & 192- & 025020 & faratoro & avermelhado, & de inundação & \\
\hline & K10/10 & & Serra Inferior) & $287^{* *}$ & $\mid 0,25-0,29$ & & fino, delgado. & & \\
\hline & $\mathrm{J} 20-\mathrm{K} 10^{* * *}$ & & $\begin{array}{l}\text { 2,7 (Rio da } \\
\text { Serra Inferior?) }\end{array}$ & $90-100$ & 0,09 & Paralelo & $\begin{array}{l}\text { Arenito médio } \\
\text { a grosso, siltito } \\
\text { e argilito } \\
\text { avermelhado }\end{array}$ & $\begin{array}{l}\text { Fluvial, } \\
\text { eólico, } \\
\text { lacustre raso }\end{array}$ & $\begin{array}{l}\text { Fm Serraria e } \\
\text { parte da Fm } \\
\text { Bananeiras }\end{array}$ \\
\hline
\end{tabular}

* devido à limitação da resolução bioestratigráfica e às incertezas na correspondência com a cronoestratigrafia internacional, os intervalos de tempo devem ser considerados com cautela.

** devido ao grande número de falhas, pode haver algum componente de afinamento tectônico.

*** intervalo não estudado neste trabalho, provavelmente composto por mais de uma seqüência de $3^{\mathrm{a}}$ ordem.

gipe, Garcia (1991) descreveu litologias semelhantes, com presença constante de gretas de ressecamento e paleossolos, indicativos de ambiente lacustre raso e/ ou planícies de inundação. Em afloramentos, também são freqüentes as camadas delgadas, porém extensas, de arenitos com base erosiva e Seqüência de Bouma, produto de fluxos hiperpicnais que adentravam no lago raso. Algumas delgadas intercalações de arenito muito 


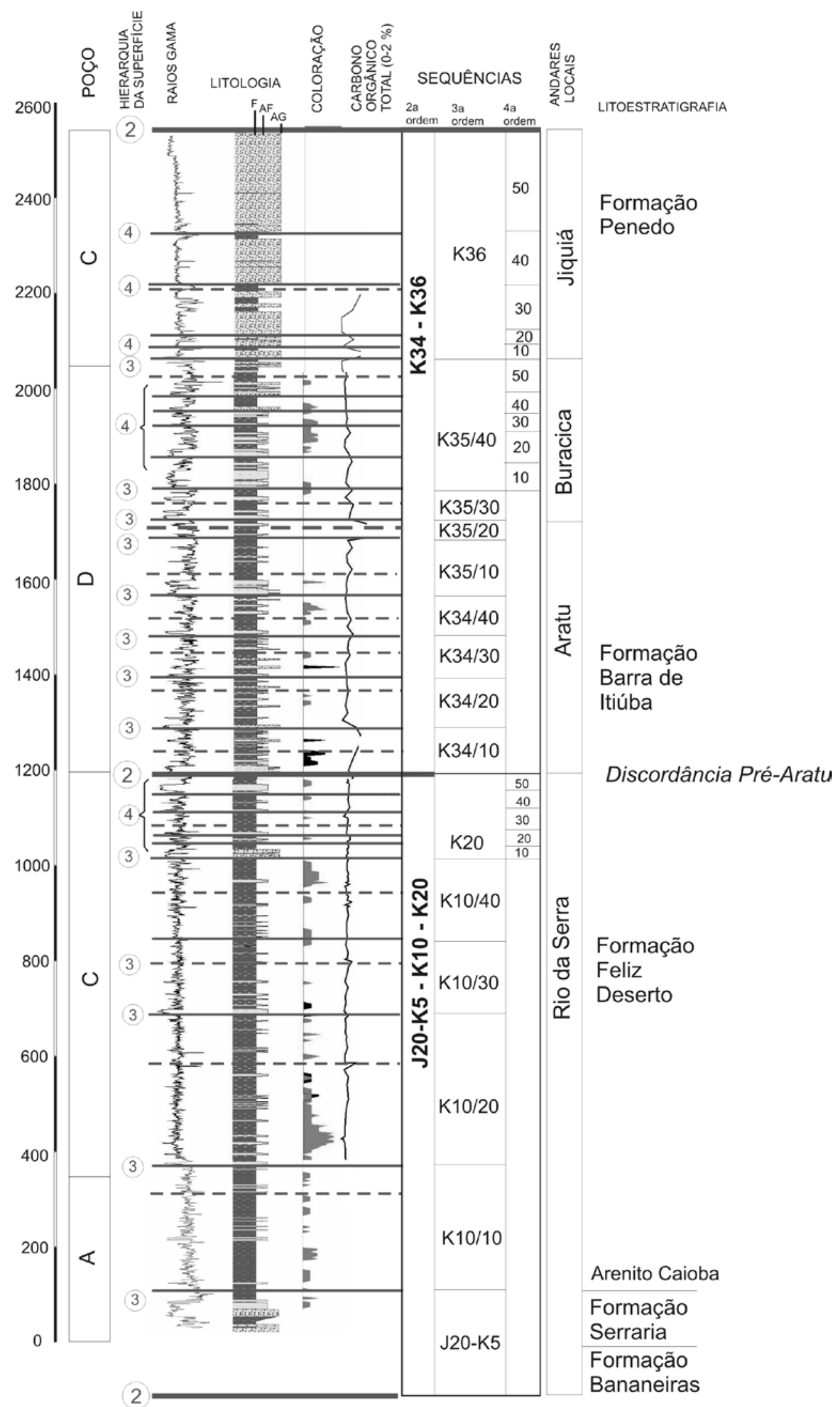

Figura 5 - Perfil composto com os poços A, Ce D (localização na figura 2). A hierarquia das superficies é definida pelos números nos círculos, e sua natureza pelo traço horizontal (contínuo para limites de seqüência e tracejado para superficies de máxima inundação). As litologias foram agrupadas segundo a granulometria: $F$ para pelitos, $A F$ para arenitos muito finos a finos e AG para arenitos médios a grossos. A curva de coloração dos sedimentos representa o percentual relativo de folhelhos negros (cor preta) e vermelhos (tom cinza). Os poços apresentados em escala reduzida nas seções estratigráficas das figuras 8,9 e 12 seguem este padrão. 


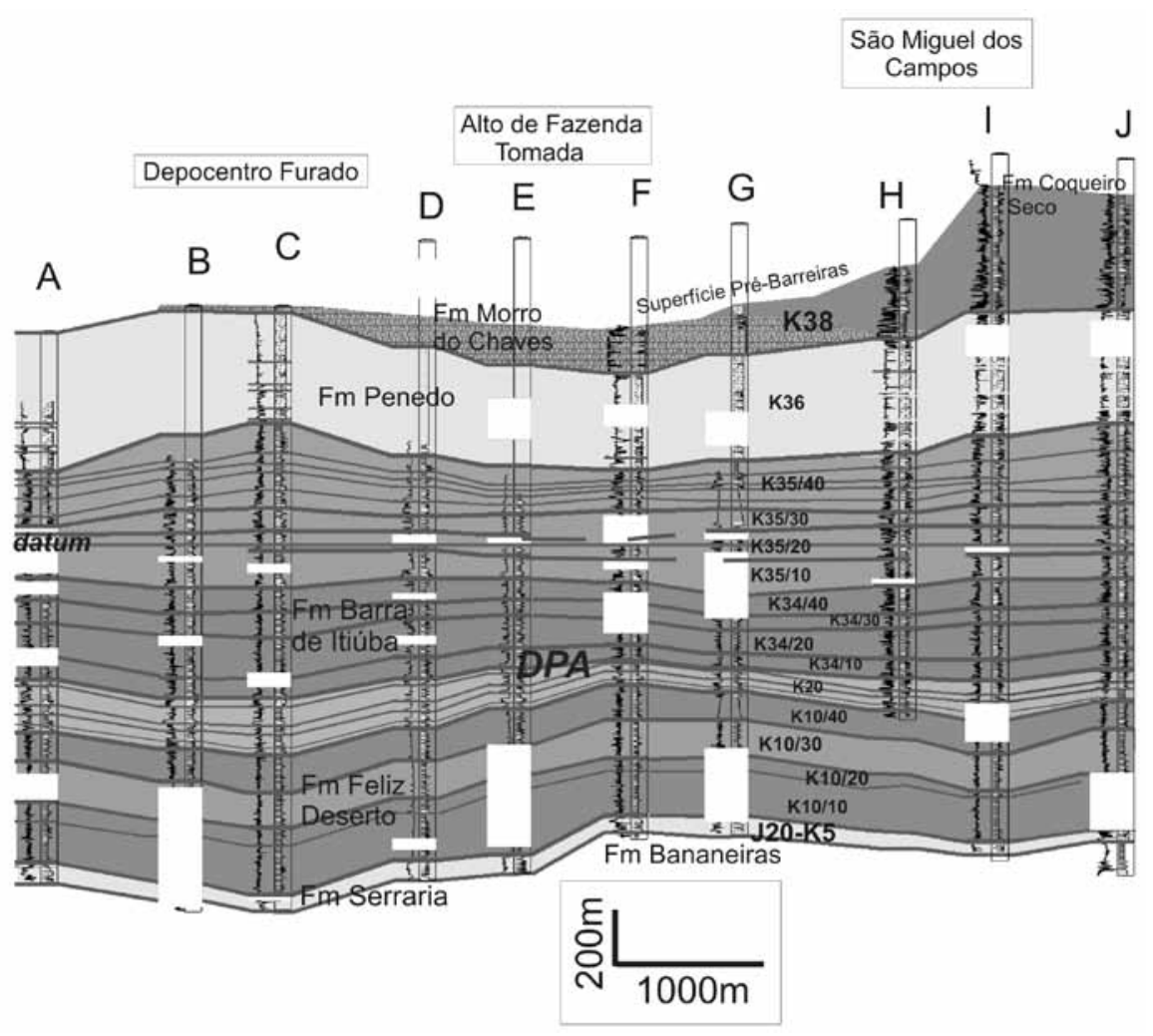

Figura 6 - Seção estratigráfica mostrando as seqüências de $3^{a}$ ordem. Datum na Superficie de inundação máxima da Seqüência K35/20. Os espaços em branco correspondem às ausências estratigráficas devido às falhas. DPA = Discordância Pré-Aratu. Linhas grossas e finas representam limites de sequência de $3^{a}$ e $4^{a}$ ordem, respectivamente.

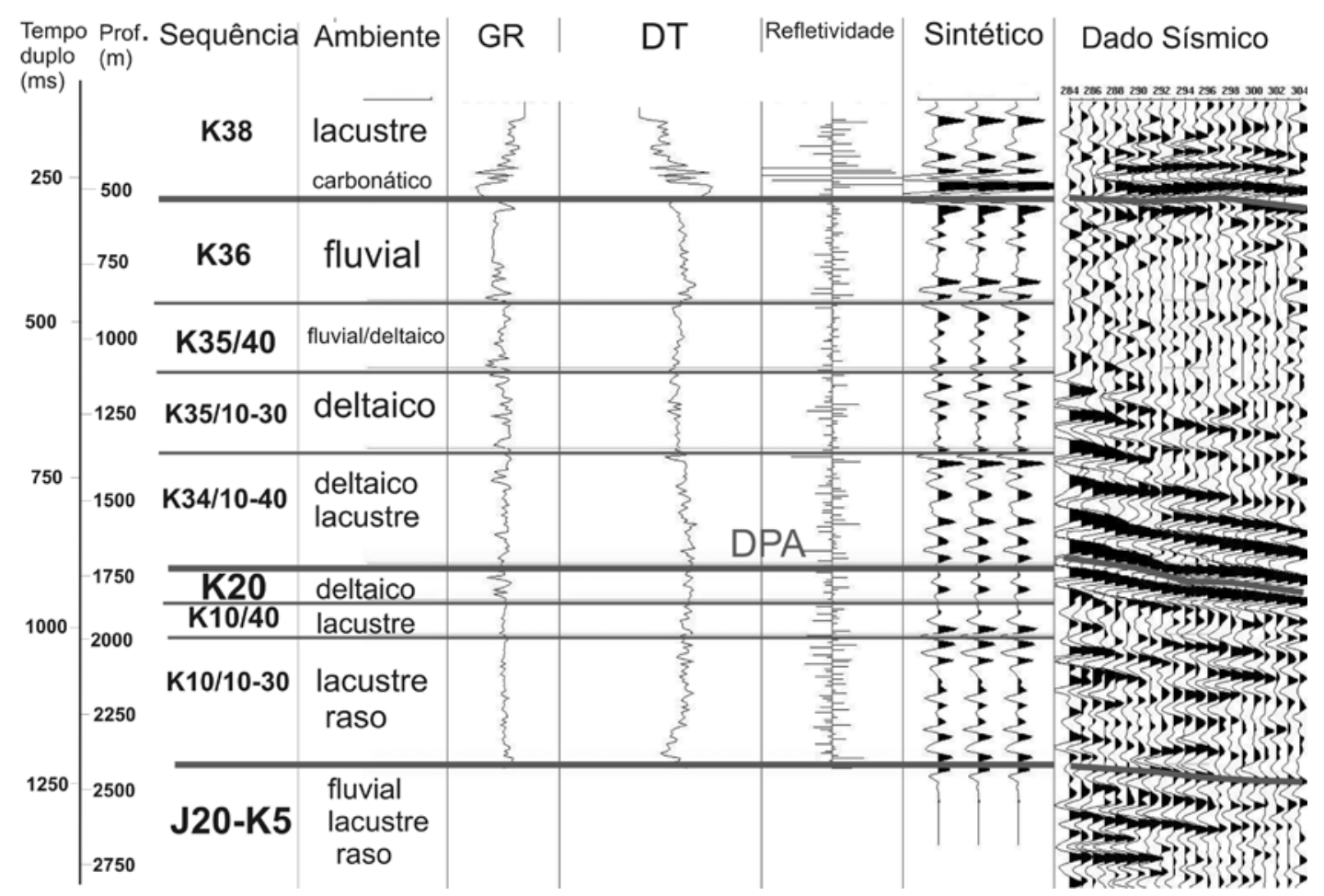

Figura 7 - Expressão em sismograma sintético (Poço K) e dado sísmico (amplitude) das seqüências deposicionais. Notar as sismofácies a partir da base da K34/10, passando de um padrão planoparalelo (lacustre-deltaico) para transparente (fluvial) na K36. DPA = Discordância Pré-Aratu. Linhas grossas e finas representam limites de sequência de $2^{a}$ e $3^{a}$ ordem, respectivamente. 
fino, com padrão de funil nos perfis raios-gama sugerem progradações deltaicas. A pequena espessura desses depósitos, associados aos pelitos oxidados, reforça a interpretação de lago raso.

Um arenito com contato basal brusco (Superfície S248, Fig. 8), capeado por pelitos oxidados, é interpretado como um limite de $3^{\mathrm{a}}$ ordem, base da Seqüência $\mathrm{K} 10 / 20$. A discreta angularidade dessa superfície sugere o primeiro indício de tectonismo local influenciando na arquitetura estratigráfica. Essa interpretação deve ser considerada com cautela, face ao pequeno número de poços de controle que atingiram esta profundidade e a não visualização na sísmica. Na porção intermediária da seqüência K10/20 diminuem os sedimentos oxidados, e surgem ocasionalmente pelitos mais escuros, com relativo aumento do teor de carbono orgânico (Fig. 5). Acima dessa superfície voltam a ocorrer pelitos avermelhados, com intercalações arenitos muito finos, em padrão de empilhamento agradacional, até o limite da seqüência seguinte.

As seqüências K10/10 e K10/20 ocorrem de forma completa em toda a porção sul da área estudada. Mais ao norte, seu limite superior encontra-se sempre ausente por falha. A interseção das falhas F2 com F1 produziu uma ausência de seção estratigráfica de mais de $1000 \mathrm{~m}$ nesta área. Há pouca variação de espessura, que quando existente pode ser resultado de falhas de pequeno porte nos poços, ou seja, pouca atuação tectônica local interferindo na sedimentação, o que resultou em estratos paralelos (Figs. 6 e 8).

A seqüência seguinte, K10/30, possui $170 \mathrm{~m}$ de espessura média e duração de aproximadamente 2,2 Ma. Assim como a precedente, apresenta padrão de empilhamento agradacional, com difícil reconhecimento de ciclos. Sua base é marcada pelo contato brusco dos pelitos da Seqüência K10/20 com um pacote tabular, com continuidade quilométrica, de arenitos finos a muito finos, com até $10 \mathrm{~m}$ de espessura. Esses depósitos são bruscamente cobertos por folhelhos escuros (Fig. 5), seguidos de um predomínio de pelitos esverdeados a avermelhados. Eventualmente ocorrem corpos de arenitos muito finos, localmente mais desenvolvidos (espessura de até $7 \mathrm{~m}$ ). A indisponibilidade de testemunhos e de afloramentos dificulta a caracterização mais precisa desses depósitos. Assim como nas seqüências K10/10 e K10/20, há pouca variação de espessura na área, e as principais feições estruturais presentes não foram atuantes (Fig. 6). As variações de espessura observadas podem estar relacionadas à existência de falhas de pequeno rejeito seccionando poços, de difícil definição devido à carência de marcadores estratigráficos confiáveis.

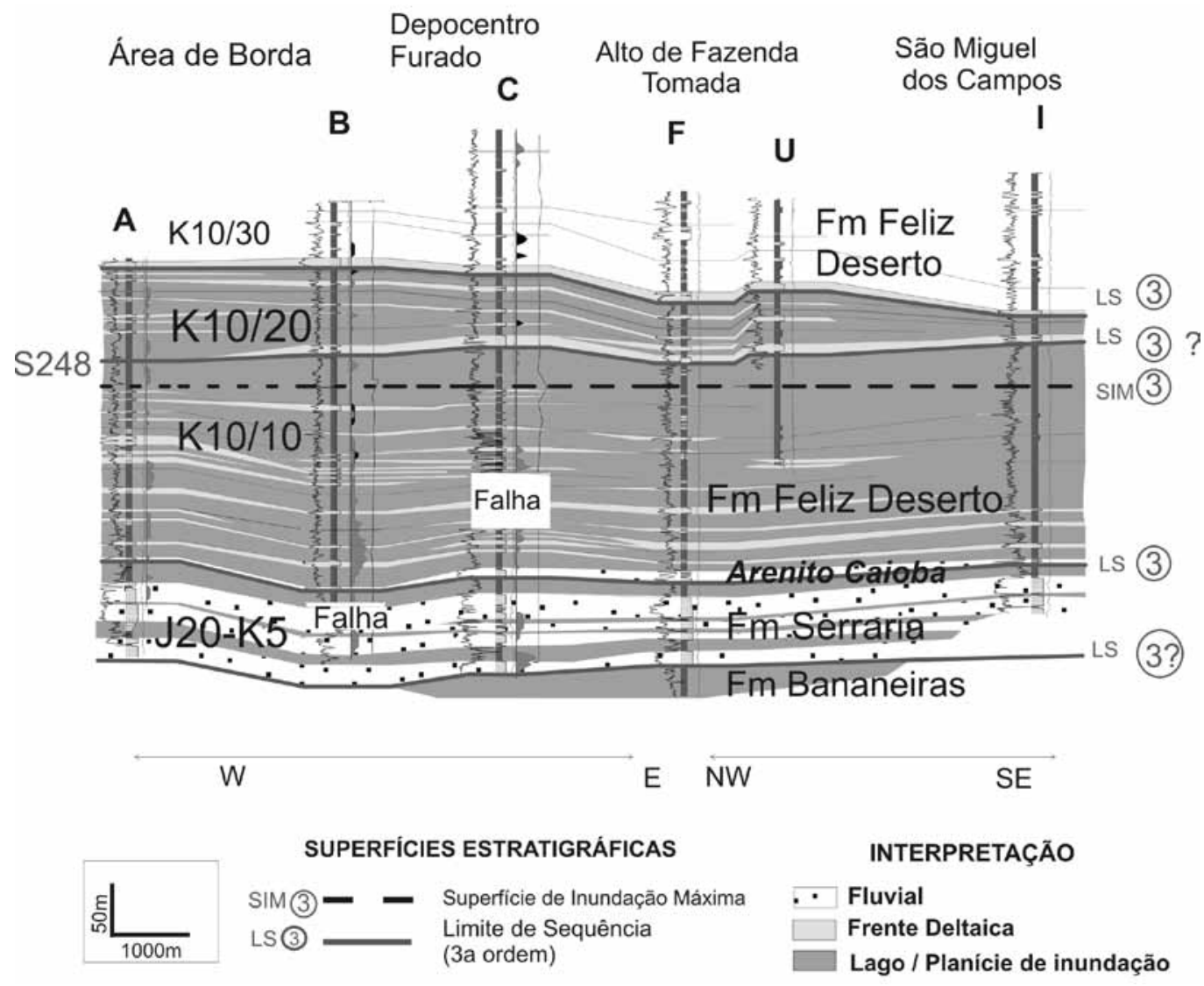

Figura 8 - Seção estratigráfica de detalhe mostrando a passagem concordante da Seqüência J20-K5 (Formação Serraria) para K10/10 (base da Formação Feliz Deserto). Não há evidência de atuação tectônica do Alto de Fazenda Tomada nesta época. 
Seqüência K10/40 Sua base é assinalada por um aumento no valor do tempo de trânsito no perfil sônico e queda da resistividade em relação à sequiência anterior. Isto sugere diferença de compactação, com soerguimento e erosão da sequência sotoposta, embora ainda sem evidências geométricas ou bioestratigráficas que possam confirmar esta hipótese. A sismofácies, de baixa amplitude e refletores de baixa continuidade, é semelhante às seqüências anteriores. Apresenta espessura em torno de $130 \mathrm{~m}$ e duração estimada em 1,2 Ma (Rio da Serra Médio).

Nem sempre o limite de seqüência apresenta depósitos arenosos basais. Quando ocorrem, são corpos delgados de arenitos finos a muito finos, com continuidade lateral de poucas centenas de metros. Não são observados folhelhos escuros, e os teores de carbono orgânico permanecem muito baixos. Não existem testemunhos nem afloramentos conhecidos.

Acima da superfície de inundação máxima, marcada onde é menor a presença de litologias avermelhadas em amostras de calha, os ciclos passam a ser bem definidos, formando conjuntos progradacionais que contém em seu topo arenitos finos a muito finos com até $5 \mathrm{~m}$ de espessura. Em direção ao topo da sequência, há um significativo aumento na freqüência de pelitos vermelhos (Fig. 5), que provavelmente indica o progressivo raseamento do lago, e precede a discordância que marca o limite da seqüência seguinte.

Seqüência K20 São os depósitos que apresentam a maior variação de espessura (100 a 250m), devido tanto ao padrão divergente dos estratos, quanto à erosão de sua porção superior, provocado por um sensível aumento na atividade tectônica durante o Rio da Serra Superior (Figs. 9 e 10). A sismofácies é caracterizada pelos refletores mais contínuos e com amplitudes mais elevadas, reflexo do maior contraste entre as camadas mais espessas de arenitos deltaicos, intercalados com pelitos lacustres.

O limite inferior é marcado pela base brusca formada por arenitos médios a grossos, com até $15 \mathrm{~m}$ de espessura e geometria tabular. Trata-se da primeira ocorrência de arenitos grossos desde o final da deposição da Formação Serraria, provavelmente resultado do tectonismo que provocou o rejuvenescimento de relevo das áreas fontes e aumento do gradiente dos rios, com deposição de sedimentos de granulação mais grossa nas áreas proximais da bacia. Esta discordância marca o limite entre as seqüências K10 e K20, que permaneciam indivisas na recente revisão da carta estratigráfica da bacia (Campos Neto et al. 2007).

A Seqüência K20 foi dividida em seqüências de $4^{\mathrm{a}}$ ordem (K20/10 a K20/50) sendo as duas superiores ausentes por erosão no Alto de Fazenda Tomada. Cada seqüência de $4^{\mathrm{a}}$ ordem é iniciada com arenitos médios a grossos, com padrão em caixa ou funil nos perfis raios-gama e espessura de até $25 \mathrm{~m}$. Testemunhos nos poços $\mathrm{AB}$ e $\mathrm{N}$ mostram significativas oscilações na lâmina d'água, com ocasional presença de folhelhos escuros, alternados com arenitos finos a grossos, com granocrescência ascendente, típicos de construções deltaicas. A constante presença de pelitos vermelhos, embora em pequena proporção, sugere períodos de exposição (Fig. 5). É a primeira manifestação de maior variabilidade litológica na Formação Feliz Deserto na área sul da Sub-bacia de Alagoas.

Nos mapas paleogeográficos regionais (Fig. 11), é percebida mais claramente a formação de deltas da provável rampa flexural na área do Campo de Furado. Mapas regionais de isópacas (Fig. 10) também mostram mudanças na configuração estrutural.

Discordância Pré-Aratu A Sequência K20 é truncada pela Discordância Pré-Aratu (DPA, Fig. 9), que se expressa como o contato brusco dos depósitos finos de prodelta/barra distal da seqüência K20 com os grossos basais da seqüência K34/10. Em um testemunho que atravessou a discordância (Poço G), uma camada de paleoalteração, representada por arenitos cimentados com calcita precoce e marcas de raízes, separa esses dois conjuntos. Em algumas áreas, o contraste litológico não é registrado, já que a Seqüência K20 também apresenta litologias semelhantes ao arenito basal da K34/10.

A seção estratigráfica de detalhe (Fig. 9) mostra o caráter angular (tectônico) da discordância, com pelo menos $100 \mathrm{~m}$ erodidos no Alto de Fazenda Tomada. O mapa de isópacas (Fig. 10) mostra essa variação de espessura produzida pelo soerguimento e erosão, e com gradiente de variação de espessura que permite estimar uma inclinação média de 2,8 dos estratos da K20 (Fig. 9) em relação à Seqüência K34/10. Isto permite caracterizar bem a discordância através de seções estratigráficas, mas o ângulo é insuficiente para ser detectado pelos perfis de mergulho.

Seqüências K34/10 a K34/40 As primeiras seqüências depositadas acima da DPA são aqui tratadas conjuntamente, devido à similaridade. Constituem a base da Formação Barra de Itiúba (como redefinida por Campos Neto et al. 2007), com espessura total média de $400 \mathrm{~m}$ e duração estimada em 5,6 Ma. São caracterizadas pelo início da ocorrência de fácies de lago mais profundo, com folhelhos negros e anomalias discretas de carbono orgânico. No dado sísmico (Fig. 7), exibem refletores contínuos, de maior amplitude em relação às seqüências anteriores, devido à alternância de depósitos de mais alta energia (arenitos fluviais e deltaicos) com depósitos lacustres. Os estratos apresentam geometria levemente divergente em direção à bacia e ao Depocentro Furado (Fig. 10). Percebe-se a continuidade da atuação do Alto de Fazenda Tomada, onde as espessuras são menores (Fig. 6). Das margens oeste (flexural?) e nordeste (axial?) chegavam as progradações deltaicas (Fig. 11).

A Seqüência K34/10 inicia-se com um trato de lago baixo composto por um pacote de cerca de $20 \mathrm{~m}$ de espessura de arenitos médios a conglomeráticos e padrão de caixa nos perfis raios gama, diretamente assentados sobre a DPA (Fig. 9). Dois poços foram testemunhados neste intervalo ( $\mathrm{G}$ e N, Fig. 9), em intervalos interpretados como depósitos de barras de desembocadura amalgamadas com canais distributários terminais. 


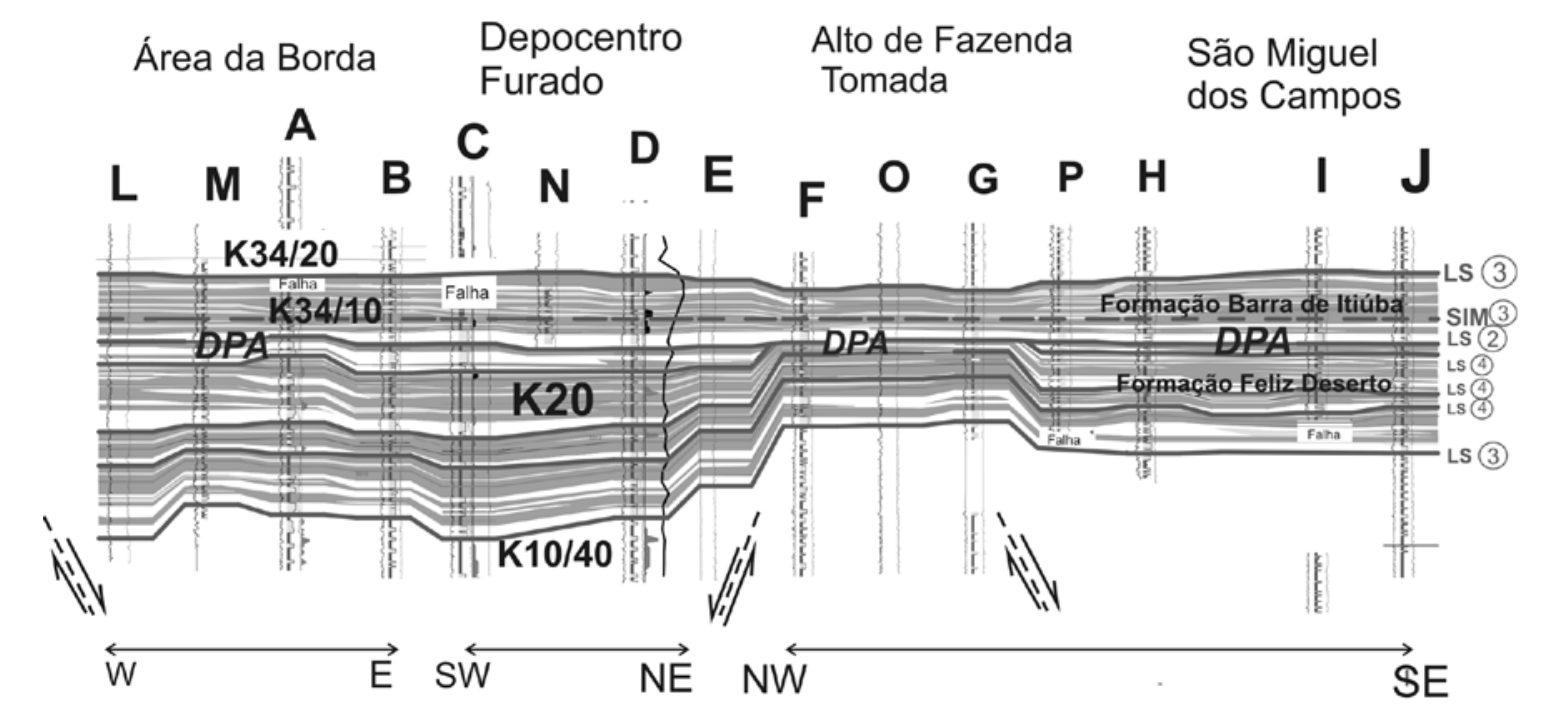

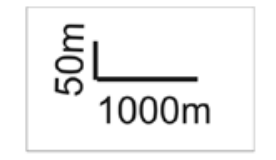

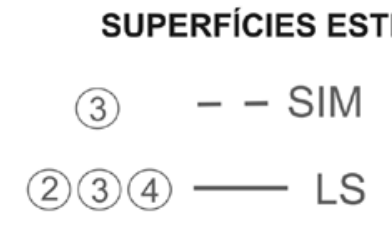

(2) (3) (4) LS
Alto de Fazenda Tomada

São Miguel dos Campos
Superfície de Inundação Máxima

Limite de Sequência (2a, 3a, $4 \mathrm{a}$ ordem)
INTERPRETAÇÃO

Barras de Desembocadura

e Canais Distributários Terminais

Barras Distais

Prodelta / Lago

Figura 9 - Seção estratigráfica, com detalhe da passagem da Seqüencia 20 para K34/10. Notar a Discordância Pré-Aratu (DPA) bem caracterizada e o Alto de Fazenda Tomada ativo.

Apresentam dezenas de quilômetros de continuidade, e são cronologicamente correlatos aos arenitos fluviodeltaicos com retrabalhamento eólico estudados por Pinho e Costa (1990), testemunhados em um poço exploratório próximo a Maceió. O início do trato transgressivo é marcado por um brusco afogamento, representado por folhelhos negros físseis, radioativos, com baixa densidade, sem bioturbação, característicos de depósitos de lago mais profundo. As anomalias de carbono orgânico total, apesar de baixas (máximo de $2 \%$ ), são as maiores desde o início da deposição das formações Feliz Deserto e Barra de Itiúba. O trato de lago alto da Seqüência K34/10 é caracterizado por conjuntos de ciclos progradacionais bem definidos, constituídos por arenitos muito finos a finos de prodelta e barra distal. Raramente se desenvolveram fácies proximais (barras de desembocadura e planícies deltaicas).

As seqüências seguintes, K34/20 a K34/40, são caracterizadas por depósitos basais formados por arenitos com granulometria média, interpretados como barras de desembocadura e foz de canais distributários. Cada seqüência de $3^{\mathrm{a}}$ ordem é progressivamente mais arenosa e com aumento para o topo na relação pelitos avermelhados/pelitos escuros. Isto sugere um gradual raseamento do lago a cada nova seqüência, já com desenvolvimento de planícies deltaicas extensas nos tratos de lago alto. Nos tratos de lago baixo, os corpos de arenito se encontram bem desenvolvidos, formando camadas com até $10 \mathrm{~m}$ de espessura, mas de menor continuidade e sem evidências de truncamento erosivo em relação aos depósitos assentados sobre o limite de maior hierarquia (DPA).

Seqüências K35/10 a K35/30 Devido à similaridade, as Seqüências K35/10 a K35/30 também foram agrupadas para fins de descrição. Apresentam idade Aratu Superior e Buracica Inferior, com duração estimada em 2,7 Ma.

A Seqüência K35/10 tem sua base em um espesso pacote de arenitos grossos, com espessura relativamente constante de $15 \mathrm{~m}$. Apresentam grande similaridade com os depósitos basais da Seqüência K34/10, embora neste caso não exista evidência de discordância angular. Folhelhos negros em contato brusco iniciam o trato transgressivo, com espessura anomalamente elevada, sugestiva de espaço de acomodação gerado pela aceleração do tectonismo. Como nas seqüências anteriores, percebe-se um suave espessamento em direção à bacia e ao Depocentro Furado, o que indica a continuidade da atuação do Alto de Fazenda Tomada (Fig. 6). As litologias não diferem das seqüências precedentes, exceto pelo ligeiro aumento da quantidade de arenitos grossos, interpretados como depósitos flúvio-deltaicos (barras de desembocadura e canais distributários terminais), que passam a dominar os tratos de lago alto.

A superfície de inundação máxima da Seqüência K35/20 corresponde ao datum regional utilizado na seção estratigráfica da figura 6 . Trata-se de um folhelho escuro com cerca de $10 \mathrm{~m}$ de espessura e ocorrência em toda a área sul de Alagoas. Neste intervalo ocorrem as maiores anomalias de carbono orgânico total (até 5\%), 

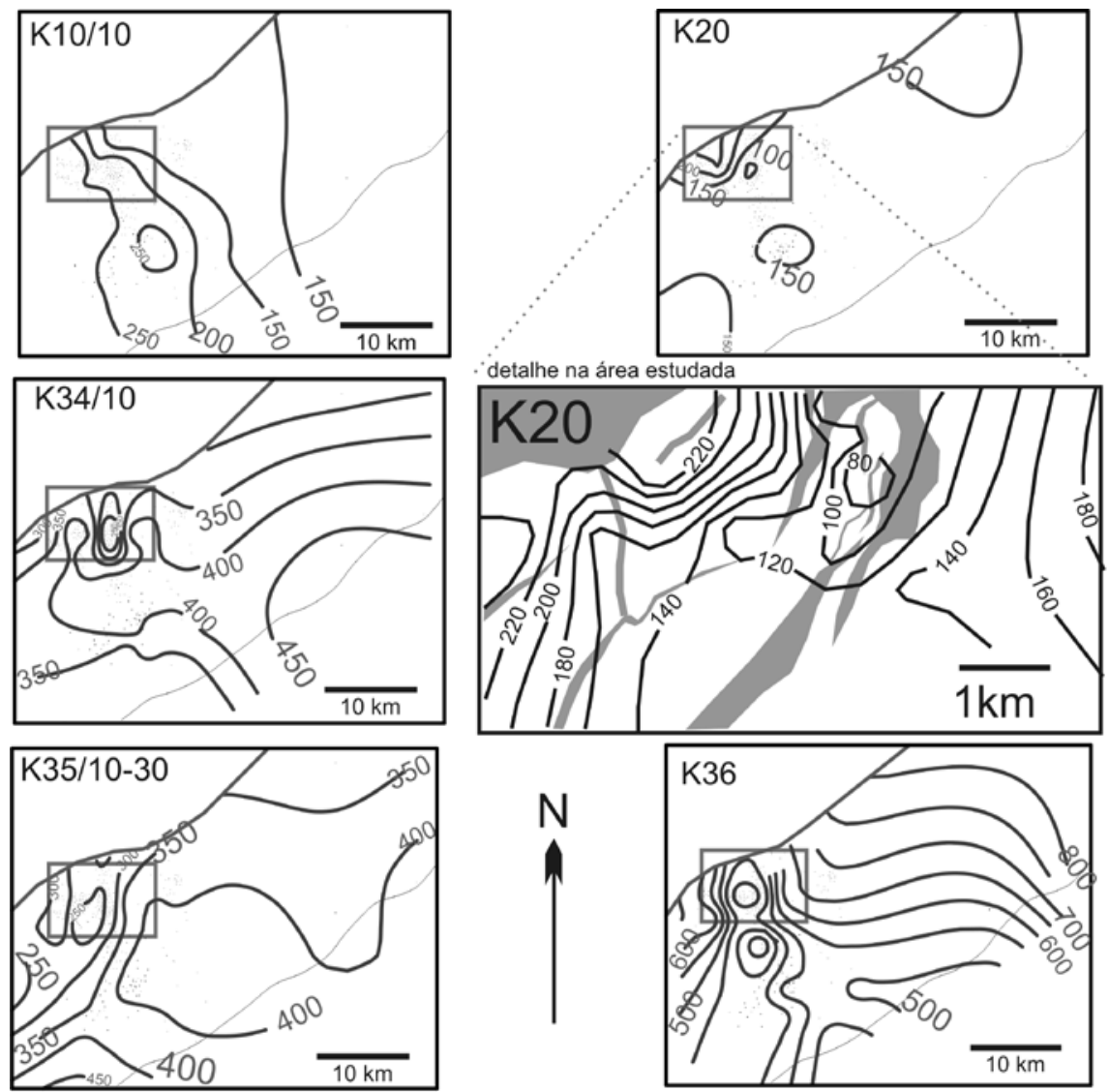

Figura 10 - Mapas de isópacas regionais (em metros). A isópaca da Sequência K10/10 mostra pouca variação de espessura na escala local. O mapa de isópacas da Seqüência K20 (no detalhe na área estudada superposto com mapa estrutural da Discordância Pré-Aratu) mostra as espessuras menores no Alto de Fazenda Tomada, devido à menor taxa de sedimentação e à erosão. As isópacas regionais das sequências K34/10 e K35/10-30 e K36 também sugerem atividade tectônica local na área de Furado. Para a Sequência K36, mostram continuidade da atividade tectônica local na área de Furado.

embora restrita a poucos metros de espessura. Acima desta superfície, passam a dominar os pelitos oxidados, associados aos depósitos fluviais que dominam a Seqüência K35/30 (Fig. 5).

Seqüiência K35/40 A Seqüência K35-40 é caracterizada pelo aumento da quantidade de sedimentos grossos, produto dos sistemas fluviais que começam a dominar o preenchimento da bacia. Engloba um intervalo estimado em 0,8 Ma no Andar Buracica Superior. Na litoestratigrafia, corresponde ao topo da Formação Barra de Itiúba, na área estudada, e à parte basal da Formação Penedo, nas áreas mais proximais, o que exemplifica o caráter diácrono dos contatos entre essas unidades (Fig. 11). Ciclos iniciados por corpos amalgamados de arenitos fluviais permitiram a subdivisão em 5 sequências de quarta ordem (Fig. 5). Prováveis depósitos deltaicos, com eletroformas em funil também são observados, principalmente nos tratos transgressivo e de lago alto.

A sismofácies é caracterizada pela alternância entre padrão paralelo e transparente (Fig. 7). Apesar de ser uma unidade predominantemente fluvial, as intercalações argilosas produzidas por afogamentos lacustres são suficientes para a definição de refletores de alta amplitude e relativamente contínuos em algumas áreas.

$\mathrm{Na}$ área estudada não existem dados de testemunhos. No Campo de Pilar, $40 \mathrm{~km}$ a nordeste, onde são importantes produtores de gás, foram testemunhados e reportados depósitos fluviais alternados com eólicos.

$\mathrm{O}$ tectonismo local se manteve atuante, evidenciado pela divergência dos estratos em direção ao Depocentro Furado e à bacia (Figs. 6 e 12). A taxa de acumulação se acelerou, devido à grande quantidade de sedimentos que chegava na bacia e cuja carga deve ter contribuído para o aumento da subsidência. Dados isotópicos (Chiossi 1997) indicam que climas mais úmidos passaram a predominar a partir do Andar Buracica, o que teria influenciado no aumento do aporte clástico.

Seqüência K36 Seu limite inferior marca a passagem litoestratigráfica da Formação Barra de Itiúba para a Formação Penedo na área estudada, no tempo Jiquiá In- 

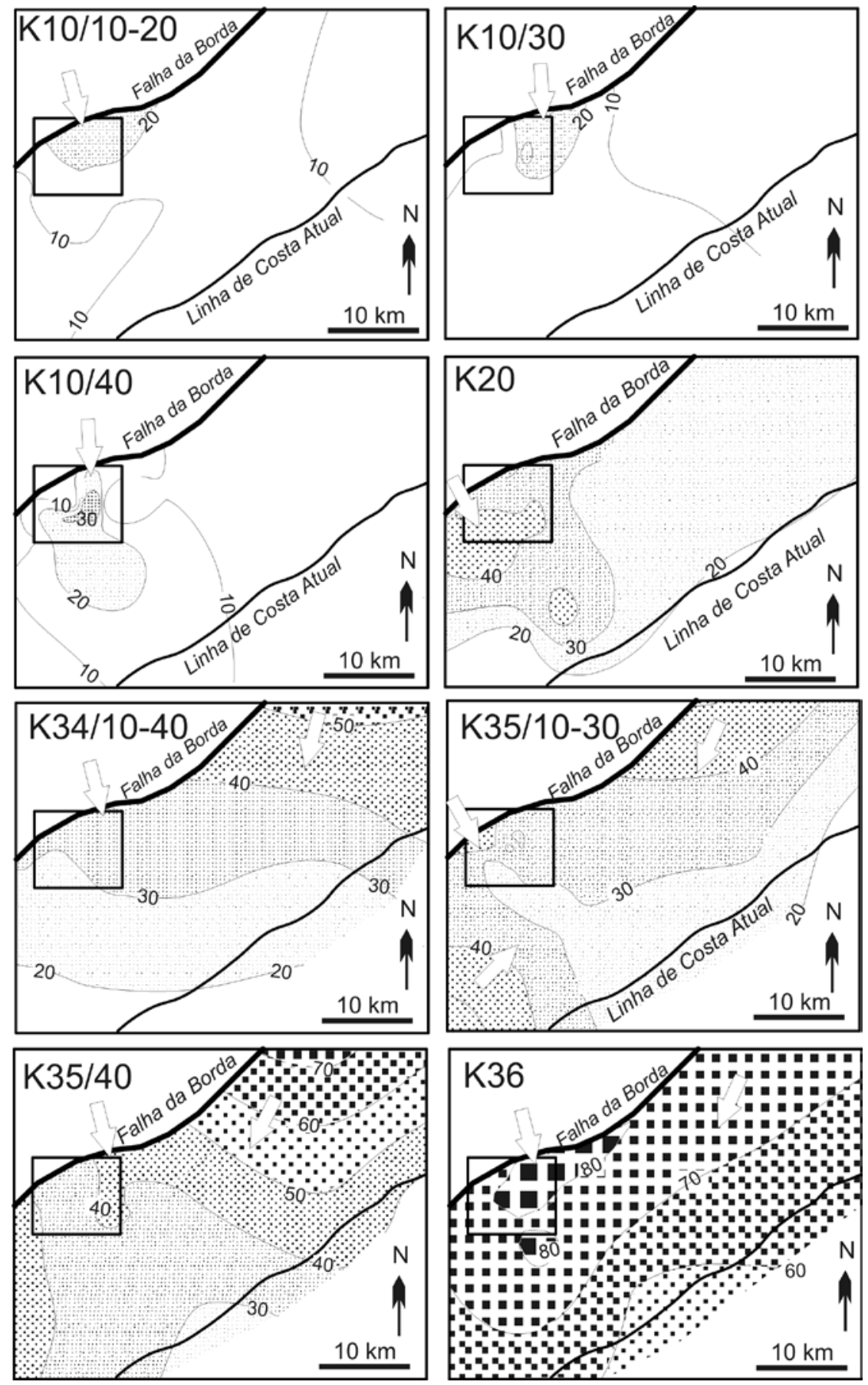

Figura 11 - Mapas regionais de isólitas de arenitos (\%) das seqüências K10/10 a K36, obtido de informações de poços. O retângulo menor situa a área do Campo de Furado, e as setas indicam direção de aporte. Notar a homogeneidade litológica, somente interrompida na Seqüência K20, indicando aporte deltaico proveniente da margem noroeste (flexural). A partir da seqüencia K34/10, percebe-se uma contribuição da drenagem vinda de nordeste (axial). As seqüências K34/10 a K35/30 são predominantemente deltaicas e a K36 fluvial/eólica. Na K35/40 os depósitos proximais correspondem à Formação Penedo, a nordeste, e os distais à Formação Barra de Itiúba.

ferior. Em relação à seqüência anterior, os sedimentos passam a ser mais grossos e mal selecionados, angulosos a subangulosos, sugerindo deposição em ambiente de rios entrelaçados. Corpos tabulares de arenitos gros- sos a conglomeráticos são interpretados como um empilhamento de barras fluviais amalgamadas e atingem $150 \mathrm{~m}$ de espessura. Embora não existam testemunhos que confirmem, arenitos limpos em caixas espessas nos 
perfis raios gama sugerem depósitos eólicos associados, como os descritos em estratos cronologicamente equivalentes no Campo de Pilar.

$\mathrm{Na}$ área estudada, a chegada desses sedimentos foi brusca e erosiva, como se pode notar na forma de truncamento angular no Alto de Fazenda Tomada (Fig. 12). A geometria dos estratos é levemente divergente em direção à bacia. Neste conjunto essencialmente fluvial, há um domínio da acomodação subaérea, onde os canais amalgamados indicam redução da acomodação e proximidade de limites de seqüência. Já a presença de canais isolados e predomínio das fácies finas da planície de inundação indicam tratos de alta acomodação (sensu Shanley \& McCabe 1994). Com isso, os limites das seqüências de $4^{\mathrm{a}}$ ordem (K36/10 a K36/50, Fig. 5) foram posicionados na base dos pacotes onde é maior a amalgamação dos canais. Apesar de dominantemente arenosa, são encontrados teores relativamente elevados de carbono orgânico nos folhelhos, possivelmente ligados à matéria orgânica de origem terrestre que se acumulava em áreas alagadas em épocas de maior acomodação.

Nos modelos de preenchimento de rifte (Lambiase 1990, Schlische 1991, Prosser 1993), esse tipo de sucessão representa a fase de assoreamento da bacia, no final de um ciclo tectônico, quando há um significativo aumento do aporte sedimentar em relação à subsidência, e sedimentos fluviais preenchem as regiões de baixo relevo do rifte.

A passagem para a Seqüência K38, representa- da pelas formações Morro do Chaves e Coqueiro Seco, é brusca, com as coquinas diretamente em contato com a Formação Penedo. Em sísmica, o contraste de impedância produz um refletor bastante forte (Fig.7). A continuidade da atuação do Alto de Fazenda Tomada também é percebida na Seqüência K38, na forma de uma maior espessura dos bancos carbonáticos da Formação Morro do Chaves no alto estrutural (Fig. 12).

\section{SÍNTESE DA TECTÔNICA E SEDIMENTA-} Ç̃̃O Os padrões de empilhamento e a geometria dos estratos, aliados ao mapeamento das feições estruturais da área, permitiram avaliar o papel do tectonismo regional e local na estratigrafia da área estudada, sintetizados na figura 13.

Embora a seção rifte na porção terrestre da Sub-bacia de Alagoas seja intensamente falhada (Fig. 4), quase toda a deformação, representada por um grande número de falhas que podem atingir rejeitos de milhares de metros, é de idade Alagoas (Meso-Aptiano?/ Eo-Albiano?), já no final do estágio rifte. Durante a deposição das seqüências K10-K20 e K34-K36, há uma tendência de considerar que as falhas tiveram pouca ou nenhuma atuação direta na sedimentação (Chagas et al. 1993, Chiossi 1997, Hamsi \& Karner 2005). Contudo, ao se analisar com maior detalhe, percebe-se uma clara influência do tectonismo, provavelmente ligado à iniciação e propagação das falhas em profundidade.

As seqüências iniciais da Formação Feliz De-

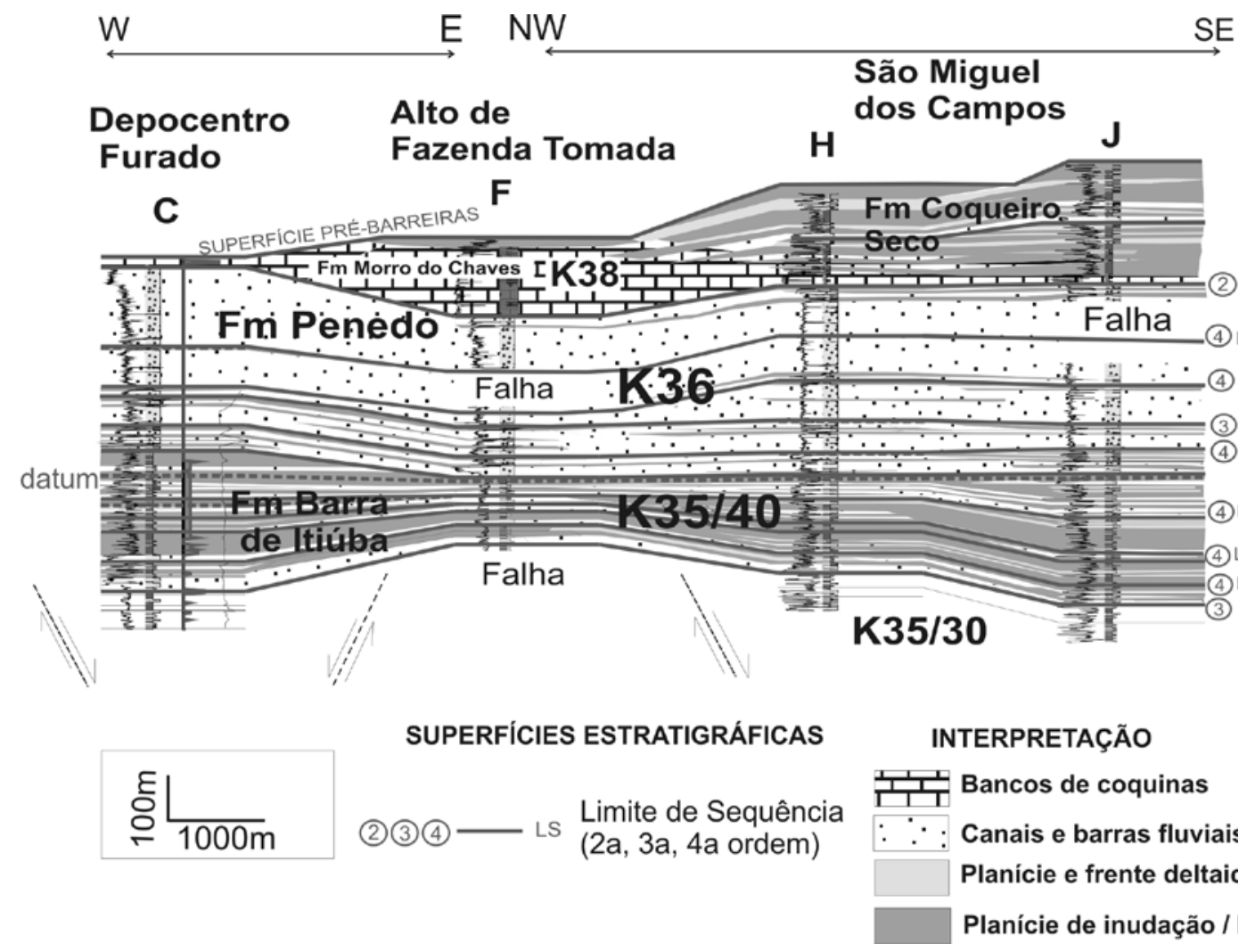

Figura 12 - Seção estratigráfica de detalhe das seqüências superiores da K34-K36, e a passagem para a Sequência K38. 


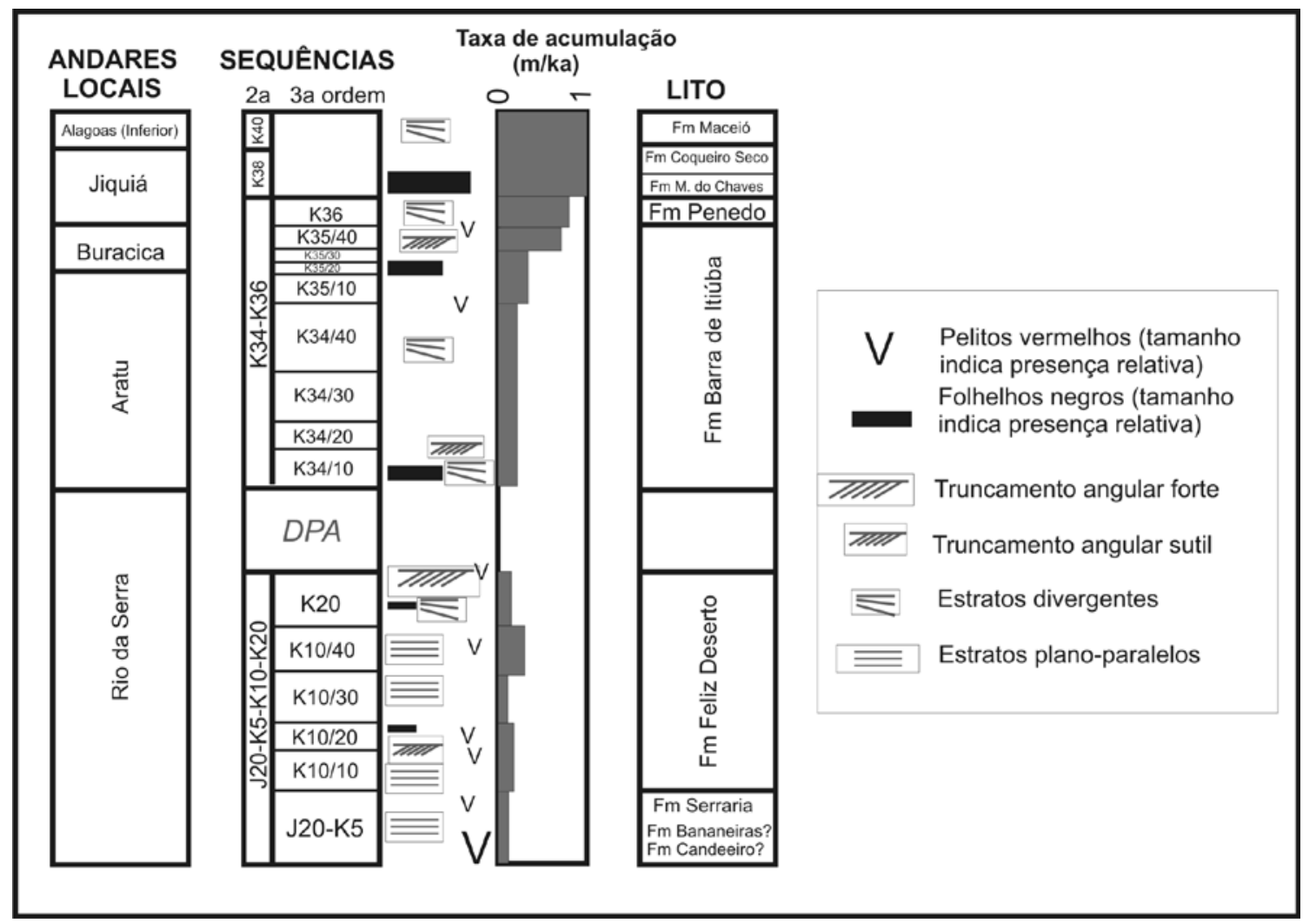

Figura 13 - Sumário estratigráfico do estágio rifte da Sub-bacia de Alagoas para a área estudada, mostrando o progressivo aumento na atividade tectônica.

serto (K10/10 a K10/40) são interpretadas como resultado de um período prolongado de acomodação relativamente alta e constante da bacia, quando o sistema flúvio-eólico da Formação Serraria deu lugar a um amplo lago raso. A passagem concordante da Seqüência J20-K5 (Formação Serraria) para a K10-K20 sugere um mesmo ciclo de $2^{\mathrm{a}}$ ordem.

O tectonismo atuou de forma crescente ao longo do Andar Rio da Serra, e é marcado pela passagem dos estratos paralelos das seqüências de $3^{\mathrm{a}}$ ordem $\mathrm{K} 10 / 10$ a K10/40 para os divergentes da K20, já prenunciando o evento que culminou com a DPA. No final do Andar Rio da Serra, este lago passou a receber aporte de sedimentos fluvio-deltaicos mais grossos, interpretados como rejuvenescimento tectônico das áreas fontes.

A atividade tectônica é evidenciada pela primeira ocorrência de geometria divergente em direção ao Depocentro Furado e à bacia, com afinamento no Alto de Fazenda Tomada, que começou a ser ativo neste período (Fig. 9). Paralelamente, ocorreu uma mudança climática, já que na passagem do Andar Rio da Serra Médio para Superior, o clima regional se tornava mais seco (Chiossi 1997, Bueno 2004).

Um evento tectônico importante, provavelmente relacionado à mudança na direção de propagação do rifte (Bueno 2004), ocorreu no final do Andar Rio da Serra, quando os estratos anteriormente depositados sofreram soerguimento regional e exposição subaérea, seguida de nova fase de subsidência. O resultado é a discordância angular Pré-Aratu, sobre a qual se assentam arenitos fluvio-deltaicos com grande continuidade lateral, bruscamente cobertos pelos primeiros depósitos de lago relativamente profundo. Apesar disso, em geral as ocorrências de lago mais profundo são breves, restritas a poucos metros de espessura.

A seqüência de $2^{\mathrm{a}}$ ordem K34-K36 (formações Barra de Itiúba e Penedo) é formada por 9 seqüências de $3^{a}$ ordem (K34/10 a K36) com tendência geral regressiva, cada qual iniciada por depósitos fluvio-deltaicos. Apesar da paleogeografia provavelmente ainda não configurar um "rifte clássico", esses depósitos seriam, na hierarquia de $3^{a}$ ordem, um "trato de inicio de rifte" (sensu Prosser 1993). Os tratos transgressivos são compostos por ciclos retrogradacionais, que culminam com depósitos lacustres relativamente profundos (folhelhos negros), um "trato de clímax de rifte" de $3^{a}$ ordem, quando a acomodação produzida pela subsidência tectônica e pelo clima úmido foi superior ao aporte de sedimentos. Os tratos de lago alto se caracterizam pelos conjuntos de ciclos progradacionais bem definidos, que tendem a desenvolver planícies deltaicas nas seqüências superiores, já em época de quiescência tectônica ao final de um pulso de subsidência. A Seqüência K35/40, quando os ciclos granodecrescentes (fluviais) passam a dominar, marca a passagem litoestratigráfica gradual da Formação Barra de Itiúba, nas áreas distais, para Penedo, nas áreas proximais. A última seqüência, K36, registra o assoreamento fluvial do rifte, correspondendo 
à Formação Penedo em toda a sub-bacia de Alagoas. Um diagrama esquemático de formação de seqüências de $2^{\mathrm{a}}$ e $3^{\mathrm{a}}$ ordem é apresentado na figura 14.

Ao se analisar a evolução do padrão dos estratos, observa-se a existência de um paleoalto coincidente com o atual Horst de Fazenda Tomada, e um baixo localizado a oeste, o Depocentro Furado. Os primeiros estratos divergentes, a partir da Seqüência K20, se espessam em direção à bacia e ao depocentro, com truncamentos erosivos e onlap em direção às falhas, $\mathrm{o}$ contrário do que se esperaria em falhas ativas aflorantes. Esta geometria se ajusta ao mecanismo de dobras de crescimento, relacionadas à iniciação e propagação de falhas em profundidade (fault propagation folds), típicas dos estágios iniciais de rifteamento (Schlische 1995, Gawthorpe el al. 1997, Ford et al. 2007). Neste modelo, há o maior acúmulo de sedimentos no sinclinal, e afinamento na anticlinal, inclusive com possibilidade de erosão nos altos, associada à rotação produzida pelo crescimento da dobra. Com a continuidade da propagação da falha, esta pode atingir a superfície, iniciando assim a geometria típica com espessamento de sedimento junto à falha, o que não chegou a ocorrer até o final da Seqüência K34-K36. A inexistência de conglomerados associados e de variações laterais de fácies reforça a idéia do mecanismo de dobras de crescimento condicionando a arquitetura estratigráfica, sem a ruptura de falhas na superfície. A atual falha de borda, se existente, provavelmente se localizava além do atual limite da bacia. Uma idealização dessa evolução é apresentada na figura 15. A F19 também se encontrava em processo de iniciação desde a Sequência K20, mas somente evoluiu para a condição de falha de borda no tempo Alagoas. A duração desse comportamento, cerca de 20 milhões de anos, sugere propagação lenta e prolongada das falhas em profundidade, com a maior parte da geração de espaço produzida por deformação dúctil. A subsidência diferencial na região do Alto de Fazenda Tomada, embora evidente e prolongada, não foi suficiente para a formação de barreiras nos sistemas deposicionais, ou de controlar as variações faciológicas nas seqüências K10-K20 e K34-K36. Aparentemente, todo o espaço gerado na subsidência diferencial foi rapidamente preenchido pelos sedimentos que chegavam à bacia. A manutenção ou mesmo subida do nível de base da bacia, durante o crescimento da estrutura, prevê esse tipo de feição, denominada on-structure (Patton 2004). A atividade do Alto de Fazenda Tomada perdurou pelo menos até o Andar Jiquiá (Sequência K38), com a deposição de bancos de coquinas nas áreas elevadas (Fig. 6). O Alto de Fazenda Tomada serviu posteriormente, no Andar Alagoas, como uma área de nucleação do sistema de falhas conjugadas de grande rejeito atualmente existentes na área.

O tectonismo deve ter sido o principal condicionante na deposição das seqüências de longa duração $\left(2^{\mathrm{a}} / 3^{\mathrm{a}}\right.$ ordem), sendo mais brando nos períodos iniciais (K10/10 a K10/40) e finais (K36). Variações climáticas também tiveram seu papel, amplificado nas épocas de tectonismo mais brando. Assim, a passagem da Seqüência J20-K5 (Formação Serraria) para a K10/10 (sedimentos finos da Formação Feliz Deserto) poderia ser conjuntamente associada a uma mudança para clima mais úmido.

$\mathrm{Na} 4^{\mathrm{a}}$ ordem (dezenas a centenas de milhares de anos), os pulsos de deformação de alta freqüência não


Figura 14 - Diagramas esquemáticos da sedimentação das sequências de $2^{a}$ ordem J20-K5, K10-K20 (A) e K34-K36 (B), as quais apresentam histórias evolutivas distintas. O modelo para deposição de uma sequência de $3^{a}$ ordem é apresentado em (C). TLB=trato de lago baixo, TT=trato transgressivo, TLA=trato de lago alto, $A C=$ acomodação, $A P=$ aporte de sedimentos. 
$\mathrm{K} 10 / 10-40$
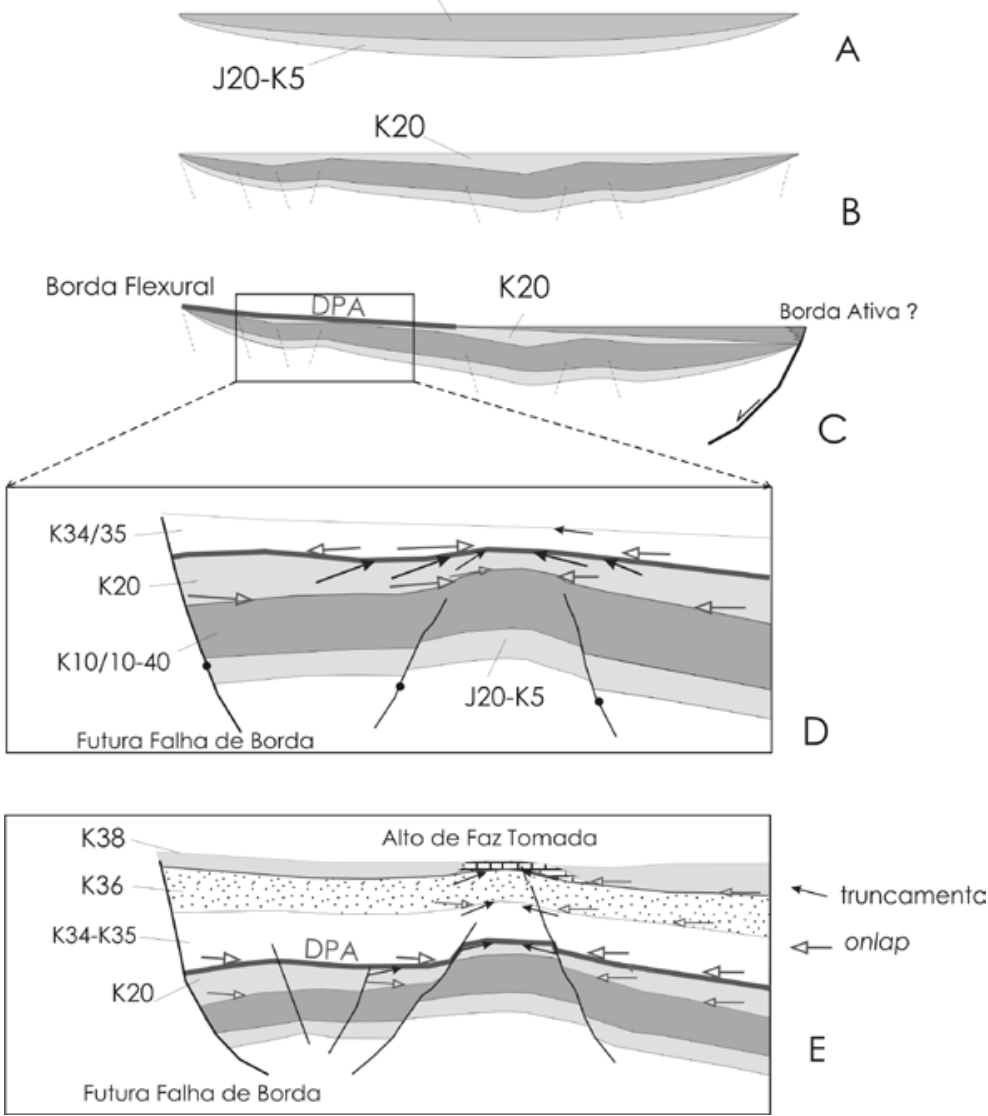

Figura 15 - Evolução tectono-estratigráfica esquemática da área estudada, no contexto da Bacia de Sergipe-Alagoas. A) Deposição das Sequências J20-K5 e K10/10 a K20 em um amplo sinforme; B) Formação de falhas em subsuperficie e de dobras de crescimento associadas, durante a deposição da K20; C) Soerguimento regional com a geração da Discordância Pré-Aratu; D) detalhe na área estudada, com deposição da K34-K36 e atuação local do Alto de Fazenda Tomada (TLB=trato de lago baixo, TT=trato transgressivo, TLA =trato de lago alto); E) Continuação da atuação do Alto de Fazenda Tomada, inclusive controlando a deposição das coquinas da Formação Morro do Chaves (Seqüência K38). Sem escala. seriam suficientes para gerar acomodação significativa, sendo os eventos climáticos condicionantes mais importantes na ciclicidade, principalmente em relação ao aporte de sedimentos. Nesses ciclos climáticos, devido à condição de lago aberto e ao clima predominantemente úmido da época (Chiossi, 1997), as oscilações do nível absoluto do lago provavelmente eram de pouca amplitude (Fig. 14).

CONCLUSÃO A análise estratigráfica em um campo maduro que preserva de forma praticamente completa os depósitos do início do rifte da Bacia de Sergipe-Alagoas permitiu a obtenção de informações importantes para o conhecimento da bacia.

A passagem concordante da Formação Serraria (J20-K5) para a Formação Feliz Deserto (K10-K20) sugere o agrupamento em uma mesma seqüência de $2^{\mathrm{a}}$ ordem, produto das primeiras manifestações do rifte. A Seqüência K10-K20 é formada por depósitos predominantemente pelíticos depositados em lago raso, com estratos paralelos nas seqüências iniciais, passando para um padrão divergente na seqüência superior (K20), coincidente com aumento na quantidade de sedimentos grossos, sugerindo um incremento no tectonismo. Seguiu-se um evento de soerguimento generalizado em toda a bacia, relacionado às mudanças regionais do campo de tensões, que deu origem à Discordância PréAratu. A Seqüência K34-K36, apresenta padrão geral regressivo (lacustre-deltaico-fluvial) típico de preenchimento de rifte. Suas primeiras seqüências de $3^{\mathrm{a}}$ ordem são formadas por tratos de lago baixo, transgressivo e alto, provavelmente relacionados a início, clímax e quiescência de pulso tectônico, respectivamente. O tectonismo ainda era brando, provavelmente sem aflo- 
ramento de falhas na superfície.

Destaca-se na área estudada o Alto de Fazenda Tomada, que atuou como uma anticlinal de crescimento desde o Andar Rio da Serra Superior (Seqüência K20). Somente mais tarde, no Andar Alagoas, houve a aceleração da propagação das grandes falhas que hoje compartimentam a área, inclusive a atual borda da bacia.

Os paleoaltos que posteriormente evoluíram para expressivos horsts focalizaram a migração de hidrocarbonetos, originando campos de petróleo como o de Furado. Como existem outras situações similares na Bacia de Sergipe-Alagoas, recomenda-se estudar a história evolutiva desses altos, a fim de verificar se atuaram em sincronia com o exemplo aqui estudado.

Agradecimentos Agradecemos à Petrobras pela autorização para publicação e financiamento do programa de doutorado do autor Cláudio Borba. Aos colegas da Petrobras da UN-SEAL e ao suporte dos programas da Landmark, utilizados no desenvolvimento do trabalho.

\section{Referências}

Barreiro C.B. 2004. Integração de dados de afloramento, perfis eletrorradioativos e de georadar para análise de análogos aos reservatórios pré-rifte/rifte: um exemplo de aplicação nas formações Serraria, Barra de Itiúba e Penedo, Bacia de Sergipe-Alagoas. Dissertação de Mestrado, UFGRS, $160 \mathrm{p}$.

Bueno G.V. 2004. Diacronismo de eventos no rifte Sul Atlântico. Boletim Geociências da Petrobras, 12(2):203-229.

Campos Neto O.P., Souza Lima W., Cruz F.E.G. 2007. Bacia de Sergipe Alagoas. Boletim de Geociências da Petrobras (Cartas Estratigráficas), 15(2):405-415.

Chang H.K., Kowsmann R.O., Figueiredo A.M.F., Bender A.A. 1992. Tectonics and Stratigraphy of the East Brazil Rift System: an overview. Tectonophysics, 213:97-138.

Chiossi D.S.N. 1997. Estratigrafia de seqüências e condicionamento tectono-climático num rifte continental (Bacia de Sergipe-Alagoas). Dissertação de Mestrado, UFRGS, $204 \mathrm{p}$.

Cruz F.E.G. \& Galm P.C. 1994. Correlação das fácies sedimentares e formas de ostracodes não-marinhos dos andares Aratu e Eo-Buracica em sedimentos deltaicos da Formação Barra de Itiúba, Bacia de Sergipe-Alagoas. Geociências, São Paulo, 15(1):209-222.

Destro N. 1994. Tectonism, Stratigraphy, and Sedimentation in Sergipe and Alagoas Basins, NE Brazil: an overview. In: IAS Congress, 14, Recife, Abstracts, p.G25-G26.

Destro N. 1995. Resease fault: a variety of cross fault in linked extensional fault systems, in the Sergipe-Alagoas Basin, NE Brazil. Journal of Structural Geology, 17(5):615629.

Feijó F.J. 1994. Bacias de Sergipe e Alagoas. Boletim de Geociências da Petrobras, 8(1):149-161.

Ford M., Veslud C.L.C., Borgeois O. 2007. Kinematics and geometric analysis of fault-related folds in a rift setting: The Dannemarie basin, Upper Rhine Graben, France. Journal of Structural Geology, 29:1811-1830.

Galm P.C. \& Santos D.F. 1994. Caracterização de uma discordância de idade Pré-Aratu (Eocretáceo) na Bacia de Sergipe-Alagoas. Acta Geologica Leopoldensia, 39(2):555-562.

Garcia A.J.V. 1991. Estratigrafia, sedimentação e diagênese dos arenitos da Formação Serraria, Cretáceo Inferior da Bacia de Sergipe-Alagoas, Nordeste do Brasil. Tese de Doutoramento em Geociências, IG, UFRGS, 305 p.

Gawthorpe R.L., Sharp I., Underhill J.R., Gupta S. 1997.
Linked Sequence Stratigraphic and Structural Evolutions of Propagating Normal Faults. Geology, 6(9):795-798.

Góes R.O., Magalhães C.A.P., Alves Filho H.P.A., Gonçalves J.R., Costa M.N.C., Cortes M.H., Campos Neto O.P.A., Valverde R.S., Formoso S. 1986. Mapeamento de detalhe dos campos de Furado, Cidade de São Miguel dos Campos e São Miguel dos Campos. In: Congresso Bras.de Geologia, 34, Goiânia-GO, Anais, 4:1701-1714.

Hamsi Jr., G.P., Karner G. 2005. Revisão de seções crustais da Sub-Bacia de Sergipe através de modelagens tectonofísicas: implicações quanto aos padrões de preenchimento e quanto à evolução do fluxo térmico. In: SBG, Simpósio Nacional de Estudos Tectônicos, 10, Curitiba, Atas, p.242-245.

Lambiase J.J. 1990. A model for tectonic control of lacustrine stratigraphic sequences in continental rift basins. In: Katz B.J. (ed.) Lacustrine Basin Exploration: case studies and modern analogues. AAPG Mem., 50:265276.

Patton T.L. 2004. Numerical models of growth-sediment development above an active monocline. Basin Research, 16:25-39.

Pinho G.C. \& Costa M.N.C. 1990. Fácies Eólica na Formação Barra de Itiúba, Exemplo de Potencial Reservatório Profundo. Boletim de Geociências da Petrobras, 4(4):489-508.

Posamentier H.W. \& Allen G.P. 1999. Siliciclastic Sequence Stratigraphy - Concepts and Applications. Concepts in Sedimentology and Paleontology, 7, SEPM, Tulsa, 204p.

Prosser S. (1993) Rift-related linked depositional systems and their seismic expression. In: Williams G.D. \& Dobb A. (eds.) Tectonics and Seismic Sequence Stratigraphy. Geological Society Special Publication No. 71, p. 35-66.

Schaller H. 1969. Revisão estratigráfica da Bacia SergipeAlagoas. Boletim Técnico da Petrobras, 12(1):21-86.

Schlische R.W. 1991. Half-graben filling models: implications for the evolution of continental extensional basins. Basin Research, 3:123-141.

Shanley K.W. \& McCabe P.J. 1994. Perspectives on the Sequence Stratigraphy of Continental Strata. AAPG Bulletin, 78(4):544-568.

Manuscrito ID 17345

Submetido em 22 de abril de 2010 Aceito em 23 de novembro de 2010 